\title{
The Practice of Combining Chinese and English Culture in Fashion Design in Cross-Cultural Context
}

\author{
Yuan Zhi \\ Department of Art Engineering, Shanxi Youth Vocational College, Taiyuan, China \\ Email: zhiyuan1217ys@163.com
}

How to cite this paper: Zhi, Y. (2022). The Practice of Combining Chinese and English Culture in Fashion Design in Cross-Cultural Context. Open Journal of Social Sciences, 10, 324-354.

https://doi.org/10.4236/jss.2022.101026

Received: December 13, 2021

Accepted: January 23, 2022

Published: January 26, 2022

Copyright $\odot 2022$ by author(s) and Scientific Research Publishing Inc. This work is licensed under the Creative Commons Attribution International License (CC BY 4.0).

http://creativecommons.org/licenses/by/4.0/ (c) (i) Open Access

\begin{abstract}
The program aims to combine the unique traditional costume characteristics of China and the UK in a cross-cultural context. After two semesters of study planning, different costume designs are created by comparing and recreating traditional Chinese and Western costumes. The thesis is divided into the following parts. The first part is a literature review to analyze and compare the different characteristics of Chinese and Western traditional costumes from a theoretical level. The second part is my personal development and improvement plan, including improving my design thinking ability and establishing a clothing brand. The next part is my time planning, following two semesters to plan theoretical study and design research. Finally, through the accumulation of theory and practice, the design project will be analyzed into a preliminary design and a final design with the specific elaboration of the design based on a comprehensive comparison of Chinese and British traditional costumes.
\end{abstract}

\section{Keywords}

Chinese Culture, British Culture, Cross-Cultural Context, Fashion Design, Traditional Costumes

\section{Introduction}

With the development of society and incorporating some of the latest design concepts into the design of fashion aesthetics, another aspect is integrating the traditional culture of our different countries into the clothing design, as a breakthrough for the new generation of clothing design. For our generation, clothing design can neither be limited by the country's traditions nor imitate the West's more modern clothing design styles. Therefore, when we design clothing, we 
must draw inspiration from daily life on the one hand and continue to learn Chinese traditional culture on the other. The integration brings more and more attractive highlights. At the same time, by learning western traditional clothing design technology, using our traditional Chinese cultural symbols, integrating and innovating the two cultures, it is possible to find a new creative path for developing modern Chinese clothing design in similar design styles. Only by analyzing traditional Chinese and Western cultures and dismantling traditional clothing design can we understand the deeper connotations of clothing culture and create unique works. This article starts by comparing traditional Chinese and British clothing styles, discusses the design styles under different cultural backgrounds, and makes innovations in clothing design on this basis.

\section{Literature Review}

The first part of this chapter introduces the different cultural values of China and Britain and the application of the two cultures in product design, ideology, and other aspects. The second part summarizes the Confucian Values in China and its effect on Chinese costume.

East Asian countries such as China, South Korea, and Japan emphasize emotional dependence, cohesion, and harmonious cooperation, while Western culture focuses on individual self-needs, emotional independence, and independence (Sung \& Tinkham, 2005). East Asia promotes collectivism, values family safety, social order, and respect for traditional culture and family members or other people. It respects the courtesy of others, while Western values emphasize the characteristics of individualism, emphasizing the role of the individual and autonomy (Sung \& Tinkham, 2005).

Confucianism is "a complex system of moral, social, political, philosophical and quasi-religious thoughts that have influenced the culture and history of East Asia” (Tivel, 2012: paragraph 1). Moreover, the fundamental essence of all life exists in Confucian principles and the nature-centric worldview that runs through Chinese culture (Peterson, 1997, p. 42). Confucianism is deeply rooted in the ideology of the traditional ruling class and has had a profound impact on the social values of the Chinese people. The essence of Confucianism is to respect harmonious interpersonal relationships and maintain a stable social order and social integration (Lee \& Song, 1994). The integrity of Confucianism influenced Chinese thought and values and shaped traditional art, including painting, architecture, and traditional clothing. Confucianism is the core idea of the development of traditional Chinese clothing. These traditional costumes formed their unique art form and aesthetic concept. Under the influence of Confucian culture, their daily clothing reflects certain morals and ethics. The colors, shapes, patterns, jewelry, and accessories of traditional costumes reflect the Confucian ritual culture, forming the aesthetic concept of "rituals" and "oneness between man and nature" influenced by Confucian culture. The gentlemen, women, and filial piety embodied in traditional Chinese costumes reflect the feudal ethics of 
ancient ethics. The traditional clothing of Chinese women also contains the core of Confucian humility.

\section{Personal Development Plan}

\subsection{Overall Objective}

With the development of globalization, for clothing design, the designer's design philosophy may change with the change of cultural background. How designers treat their own culture and integrate cultural meaning into their designs and share design ideas among people of different cultural backgrounds is very important. Therefore, as a designer, understanding the design concepts under different cultural backgrounds, especially the cultural background, is also a significant factor in fashion design. In today's clothing industry, a skilled fashion designer plays a role not only as a designer but also as an interpreter and disseminator of culture (Jin, 2004). Therefore, the primary purpose of this article is to explain how different cultural backgrounds affect designers' fashion design concepts and concepts, and through the analysis and disassembly of different styles of clothing, combining Chinese and English cultures to create my style.

Short-time: Improve design thinking ability, proficiently use reflective practice skills to make the design more meaningful.

Long-time: Establish a clothing brand. First of all, interns work in the fashion design industry and accumulate work experience. Second, learn relevant knowledge of brand management. This framework sets an excellent example for the fashion industry. It abandons the traditional "sacrificing resources and environment to make money" mindset. Instead, waste can be re-used; the natural environment can be regenerated. It is a "win-win" idea (Francois, 2019).

The innovation of a business model cannot conflict with the designer's design concept. If a designer picks a renewable and eco-friendly material, the circular of recycling will be formed from the beginning (Francois, 2019).

\subsection{Summary of My Design Practice}

Fashion Design

Graphic Design

Accessories Design

Brand Management

\subsection{Strengths}

Since high school, I have often discussed how to choose my future life path with my parents. They always tell me to be a valuable person to society and live a worthy life. So since high school, I have had a very clear goal in life-to study costume design in-depth and interpret the logic behind the beauty. So I chose fashion design as my undergraduate major. I earnestly studied professional theoretical knowledge during school and seized every opportunity to put the theory into practice. I have achieved good academic performance, won many 
scholarships, participated in many campus and social activities, and won numerous awards.

During my undergraduate studies, I have excellent academic performance, deepened my professional theoretical study, and mastered a relatively complete knowledge structure. During my studies, I participated in the project "School Uniform Design for Middle School Students in Hebei Province," independently completed the work's content and achieved some meaningful project results. I can also analyze and solve problems independently, and I can integrate theory with practice in clothing design.

After graduating from undergraduate, I came to the UK to continue my postgraduate studies. The rich curriculum and critical thinking have allowed me to grow rapidly. We will have group assignments every week to discuss the setting of design details with students from different countries in the world during school. Such interactive learning exercised my English expression skills and allowed me to integrate the world culture into my design philosophy.

\subsection{Weakness}

As a fashion design student who has studied in the university for four years, my first shortcoming may be the lack of knowledge of marketing and brand management. The focus of my previous studies was mainly on clothing fabrics, patterning, or design. It rarely involves clothing marketing knowledge or brand strategy knowledge, so sometimes, there may be clothing designs that do not cater to the market well.

On the other hand, my knowledge reserve is mainly in clothing design. I may not be proficient in clothing and brand logos and lack relevant inspiration. Therefore, my knowledge reserve may have a single structure, which cannot meet the overall market demand for clothing design.

\subsection{Plan Details for Semester 1}

Personal plan:

1) Continuously develop new design thinking and learn better design methods through professional knowledge.

2) Try to do some sustainable clothing design with my knowledge.

3) Ideally, I would like to design a dress that can be worn in many ways.

Skills, knowledge, and experience: To recognize the social value of clothing design and to better use more scientific research methods to conduct continuous research in the field of clothing design.

Process and Methods:

1) Use critical thinking to read and organize literature.

2) Talk with mentors about research methods and design concepts that can be used.

3) Research sustainable clothing brands worldwide and visit these studios to learn from them. 
Problems: Although the focus is on sustainable clothing design, the degree to which detachable clothing is achievable is flawed, and even the step of printing the garment is not possible.

Conclusion: It is necessary to have a design concept with innovation and practicality, but whether or not it is achievable needs to be carefully considered in light of previous experience and reality.

\subsection{Plan Details for Semester 2}

Personal plan:

1) Establish new design ideas and themes.

2) Integrate cross-culture into fashion design.

3) Study different clothing cultures in China and the UK in depth.

4) Explore marketing strategies in the fashion industry.

Skills, knowledge, and experience: Analyzed recent fashion trends. The future development trend of clothing and possible problems is analyzed-some sustainable fabrics in fashion design.

Process and methods: Critical literature review. Talk to tutor. Talk to people in the fashion design industry. Visit some representative British cultural clothing exhibitions.

Global context: The fashion design industry has an indispensable role globally. The cultural integration of different countries is an essential process of cultural exchange. People in every country have a growing demand for fashion aesthetics.

\subsection{Design Project in Semester 2}

Week 1-Week 2

What I learned: Better time management for this semester's project. Communicate with people from different countries.

How does it relate to my project: Time management is essential for my project and urges me to plan my semester 2 in detail. And communicating with people from different countries allows me to understand their country's culture in detail, which is an essential step in my project.

What I did: I made a timeline for my project. Draw something free when I see exciting things in life. Read some literature reviews about reflective practice and action research.

Week 3-Week 4

What I learned: Overall project analysis; Action research; Cross-culture Communication.

How does it relate to my project: The planning task of the flow chart is a critical instruction tool for me to complete my project. It can help me plan well. Action research is significant for design exploration and growth knowledge, and the information collected is very reliable.

What I did: I made a rough project flow chart to plan the tasks that my project needed to complete at different times-investigated some classic British clothing 
culture. Read some literature reviews about reflective practice and action research.

Week 5-Week 6

What I learned: Cross-cultural background and global impact; Reflective practice; British clothing trends; UK clothing marketing strategy.

How does it relate to my project: Through the understanding of British clothing trends, the design ideas have become more evident. I can feel the improvement of critical thinking. It is closely related to my design concept and design theme.

What I did: In-depth research and summary of British clothing trends-developed reflective practice models. Then I applied this module to my project, attempted to combine elements of British classical clothing with contemporary clothing.

Week 7-Week 8

What I learned: The use of different cross-cultural elements in fashion; Further understanding of cultural integration.

How does it relate to my project: Through this design process, cross-cultural provided more connections in my project. The design concept is constantly improved.

What I did: Investigation of ancient Chinese costumes and accumulation of elements of that and the combination of Chinese clothing elements and British clothing. I drew some sketches and initially showed my design project's basic concept.

Week 9-Week 10

What I learned: The professional skills of costume design have improved. I learned some brand marketing strategies.

How does it relate to my project: The new improvements in different design stages have new help for my project and help further the design. The learning of brand strategy also has a new impact on the direction of my design project.

What I did: I further applied reflective practice to my design and found some ideas that are not very useful for design. Improve these useless ways and find new design methods. I learned a certain amount of brand-building knowledge and started to think about how to make my project an independent brand.

Summary of PDP

After two semesters of study, with the continuous improvement of design skills and knowledge, through the study and application of design thinking and reflective practice, my design thinking has also undergone some changes. I constantly find and improve problems in the design so that my design project can be improved.

One of the achievements I learned in the first semester is using design research methods to collect valuable materials and evidence in different explorations. However, in the last project, I realized that the concept of the first semester was difficult. Realized, these are also limited in the actual industry. There- 
fore, I need to learn to design critically.

In addition, I went to some exhibitions in the UK and showed many British classical costumes. Participating in them is one of the crucial ways to improve the ability of design criticism.

Compared with the first semester, the second semester is clearer about design direction, and it is also more feasible to design my project. However, the sustainability of clothing in the first semester still needs to be applied to this semester project, which is very important.

\section{Reflective Practice}

\subsection{Reflective Practice Module}

Through the reflective practice study, I completed the model of reflective practice, and it adapted to my design practice. It consists of six small parts: planning, research, action, observation, evaluation, and reflection (presented in Figure 1).

In my design project, I have used this model and will follow this step when each new design concept is formed so that each step of the design is closely related and then promote the next design.

\subsection{Diary of Reflective Practice}

In the process of design practice, I reflect on and practice each new design idea, which helps design research derive new ideas and new states and beneficially affect the next design. I can ensure that every step of my design is relevant and can help me provide improved solutions.

I use the recording template (shown in Figures 2-6) to record my reflective process at each stage, which shows the module of the reflective practice to provide some help for my design project.

\section{Design Project}

\subsection{Background}

\subsubsection{International Context}

For centuries, textiles and clothing styles have been among the most obvious and poignant indicators of cross-cultural interchange. With the rapid rise of globalization over the past several decades, the spread of fashion across global cultures has mirrored the changes in economy, culture, and daily life that globalization has brought.

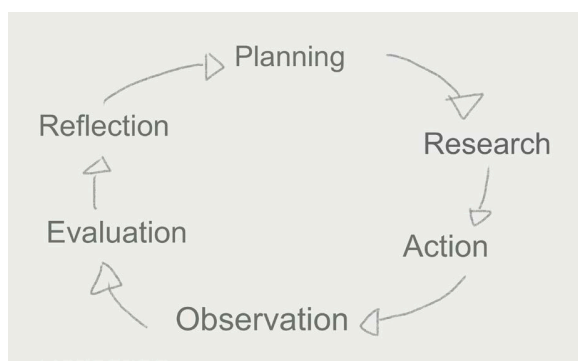

Figure 1. Design practice. 


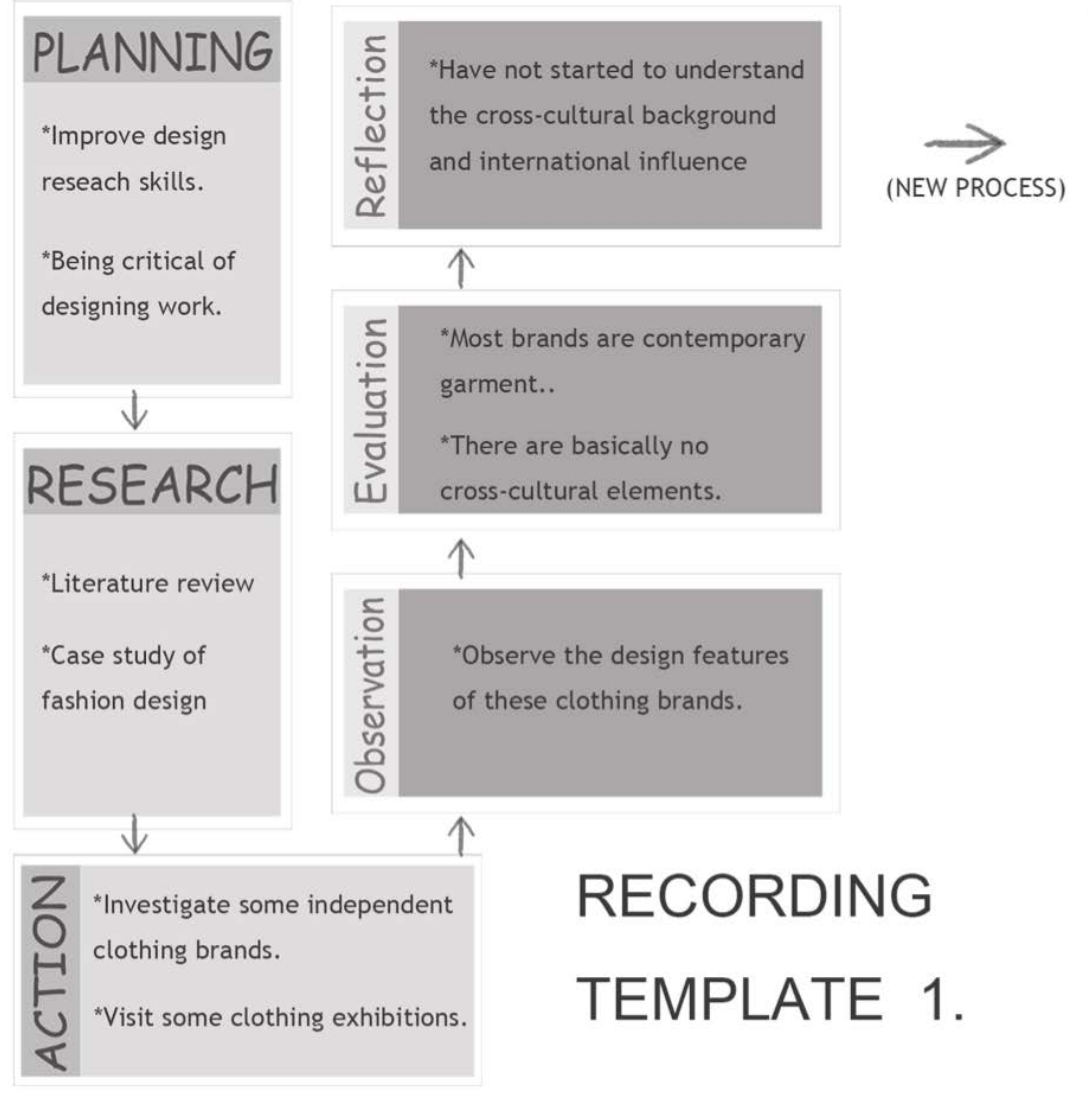

PLANNING

*Start learning and researching cross -cultural related knowledge.

* Investigated some classic British clothes

Figure 2. Recording template 1.

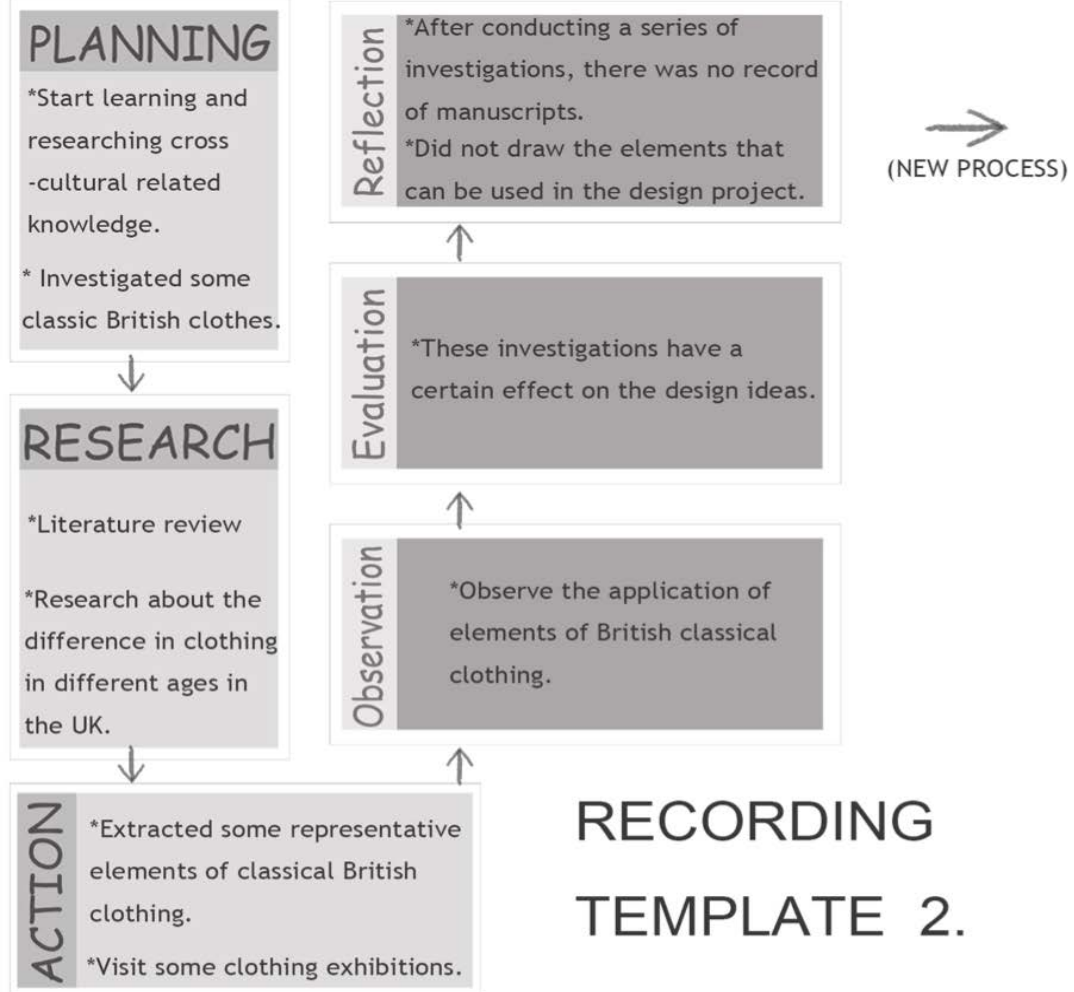

\section{PLANNING}

*Draw some initial sketches.

*Continue to investigate: critical and analysis the contemporary clothes.

Figure 3. Recording template 2. 


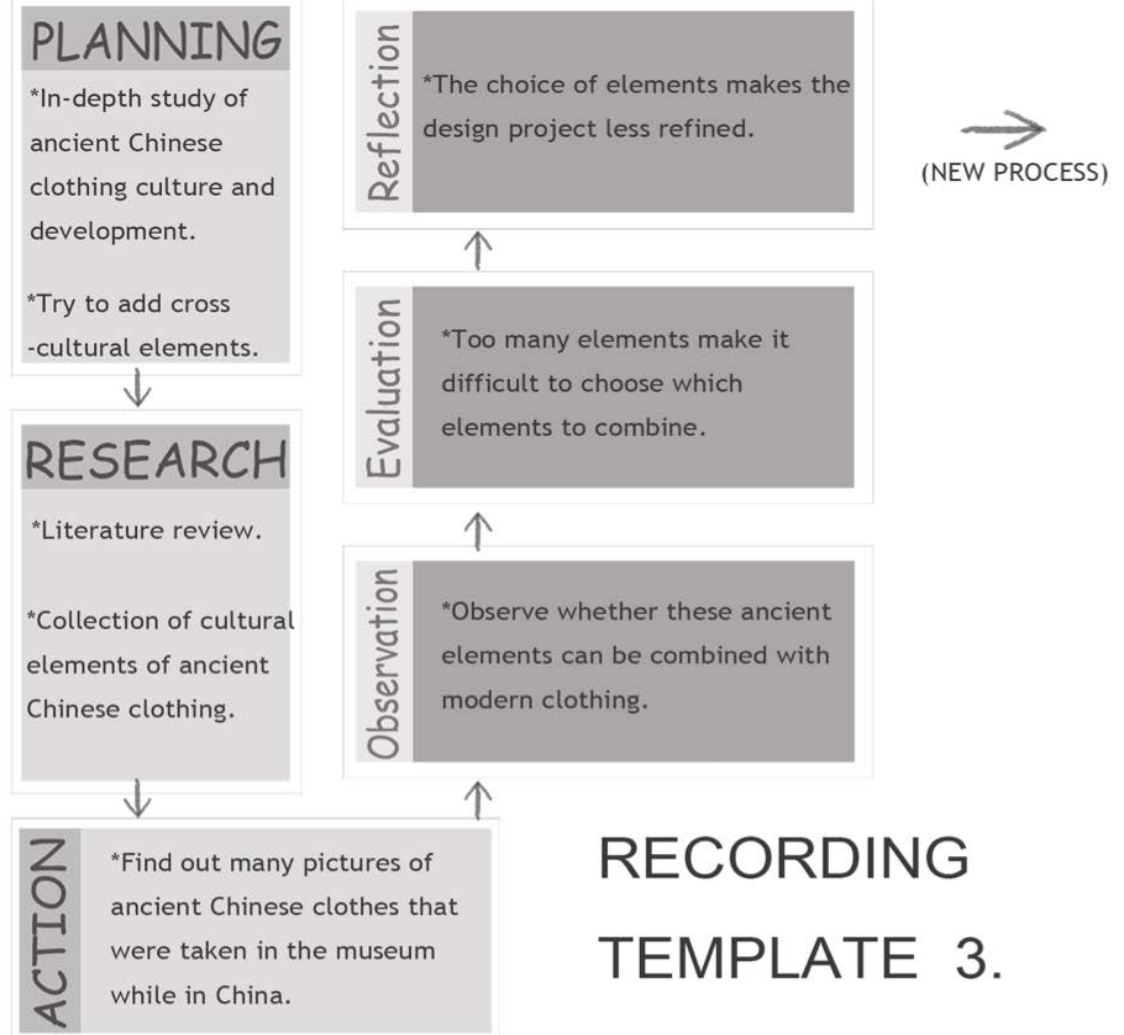

PLANNING

*Further exploration of ancient Chinese costumes and classic British clothing.

*Try to add cross -cultural elements.

Figure 4. Recording template 3.

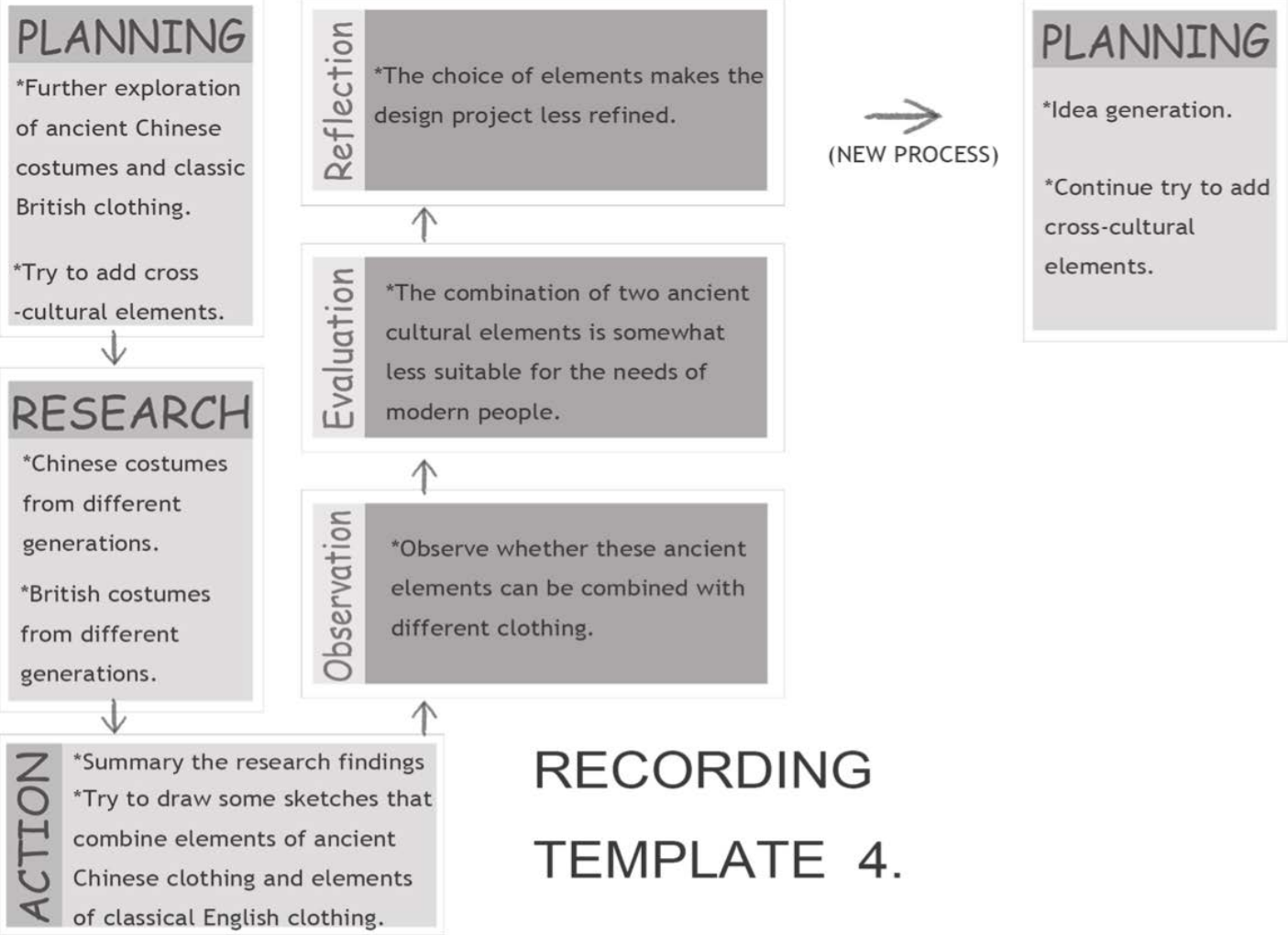

Figure 5. Recording template 4. 


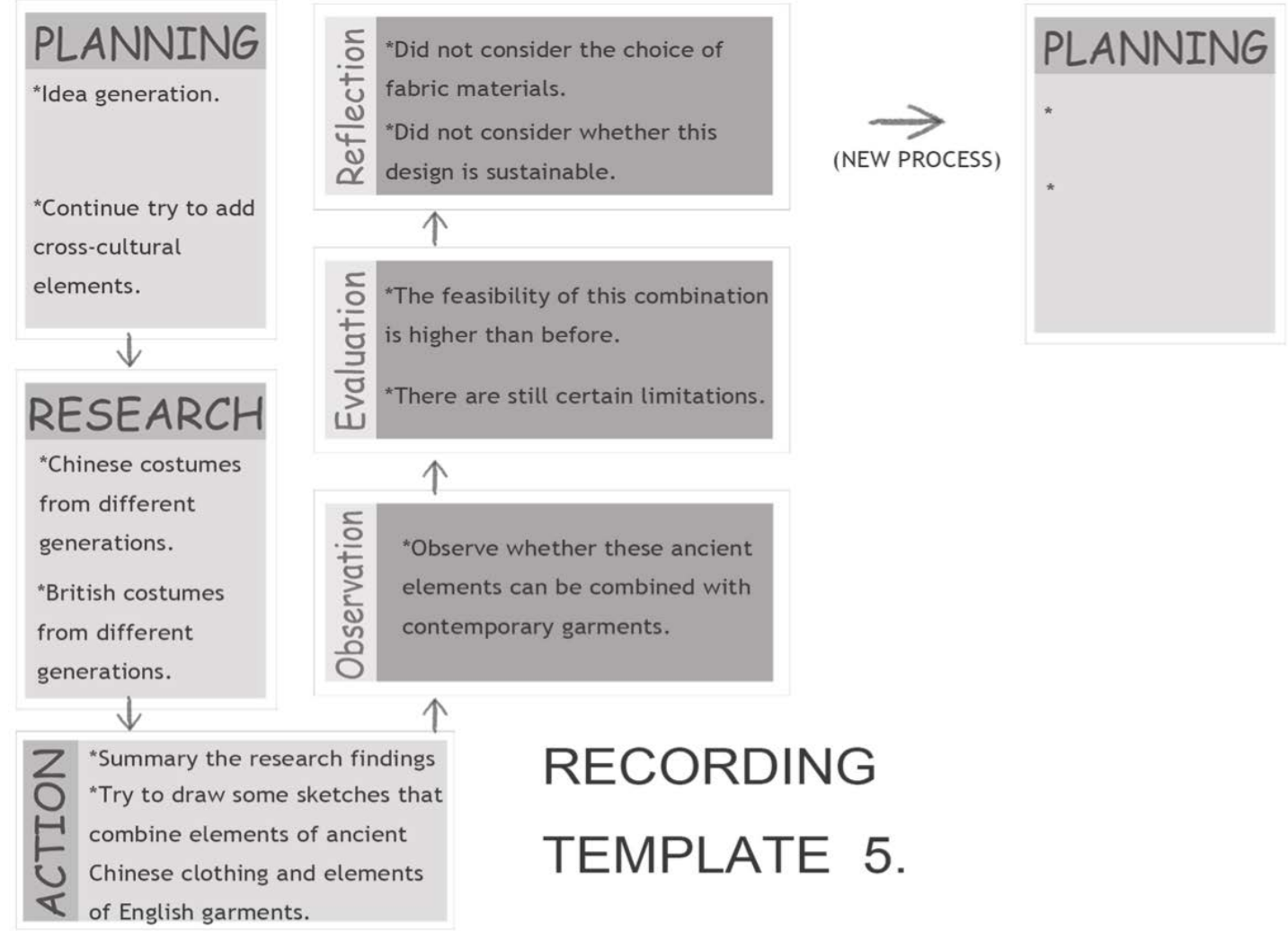

Figure 6. Recording template 5.

By studying the history and current trends in the fashion business, we address a fascinating field and better understand the complicated linkages that connect cultures and people in the modern world.

Nowadays, the influence of Chinese culture is gradually expanding in the UK, and Chinatown has also begun to develop. Many products with Chinese design attracted the attention of the British, which also means that Chinese culture continues to develop and spread in the UK. However, according to my research, Chinese cultural clothing rarely appears in the UK.

\subsubsection{The Project}

Therefore, this design practice aims to find some elements of traditional Chinese clothing and combine them with classic British clothing.

Based on my understanding of traditional Chinese costumes, I made a mind map (Figure 7) about these traditional Chinese costumes.

\subsection{Design Process}

\subsubsection{Primary Research}

Chinese traditional costumes

In the design process of this project, primary research has been widely used to collect pictures and information. The research process includes several steps: traditional Chinese clothing research, British classic clothing research, and exhibition collection. 


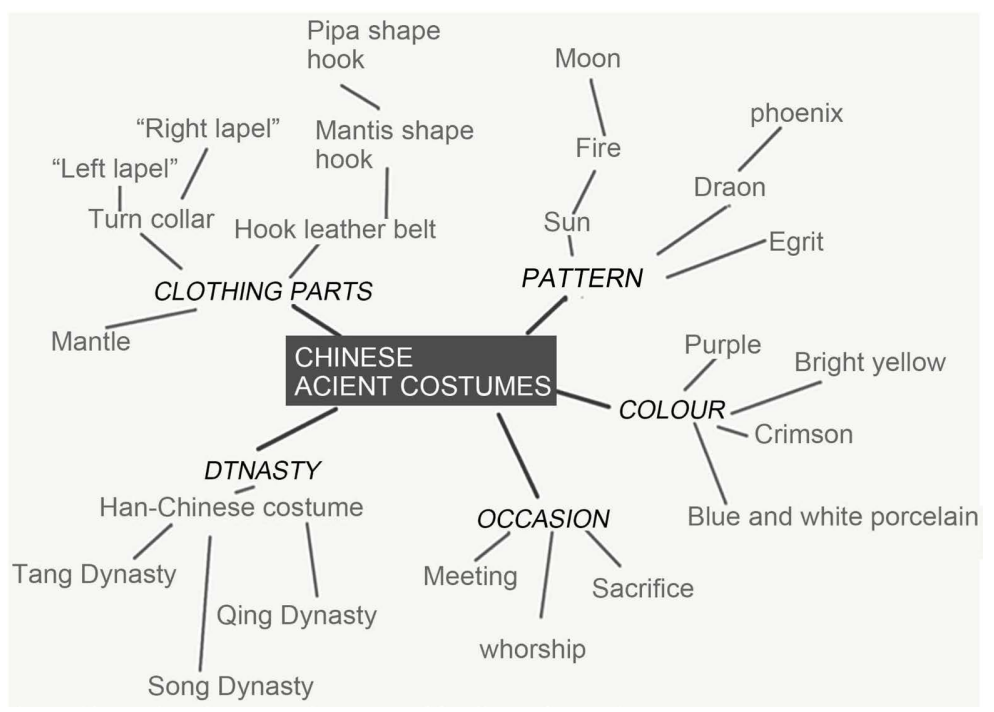

Figure 7. A mind map about these traditional Chinese costumes.

China has a long history, and clothing has different characteristics at different historical stages. Mainly lies in the collar structure, patterns, belt accessories, and colors (illustrated in Figures 8-14).

\section{British traditional costumes}

In this project, the collection of Chinese elements and the research of British clothing needs to be from traditional to modern. In the process, in addition to collecting pictures online (presented in Figures 15-19), I also saw related British classical costumes in the exhibition hall (presented in Figures 15-19).

\section{Exhibition Research}

John Rylands is a long-established library in the United Kingdom. It displays traditional British clothing and observes its characteristics up close (see Figure 20).

\subsubsection{Secondary Research}

Through the collection of traditional Chinese and British clothing, I have a general understanding of their unique characteristics (see Figure 21, Figure 22). In addition, in further research, I sorted out the development process of clothing in different periods of the two countries and extracted their respective apparent characteristics.

According to the research findings, I have developed some design points from the clothing characteristics of the two countries with sketches (see Figure 23, Figure 24).

After extracting these design points, I can make some attempts to put them into the subsequent design.

\subsubsection{Design Experiment}

Through the understanding of these elements, I began to try to blend the traditional clothing elements of the two countries, and combine modern elements to enable it to be established in daily life (see Figure 25, Figure 26). 

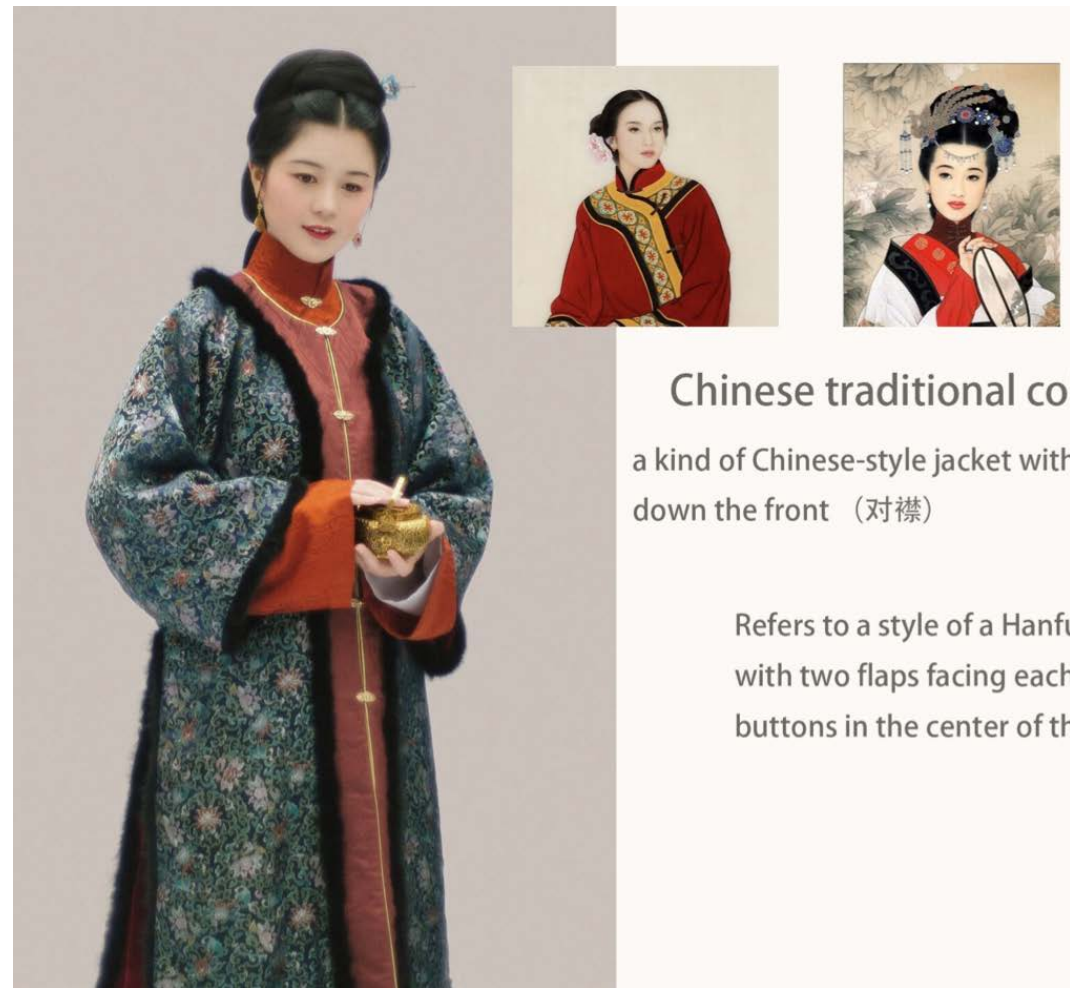

\section{Chinese traditional collar}

a kind of Chinese-style jacket with buttons down the front（对襟）

Refers to a style of a Hanfu top, with two flaps facing each other, buttons in the center of the chest.

Figure 8. Chinese-traditional clothing elements-Chinese traditional collar (https://changan-moon.tumblr.com/post/135521586943/traditional-chinese-hanfu-in-ming-dynasty-s tyle and https://imgur.com/gallery/l43zF).

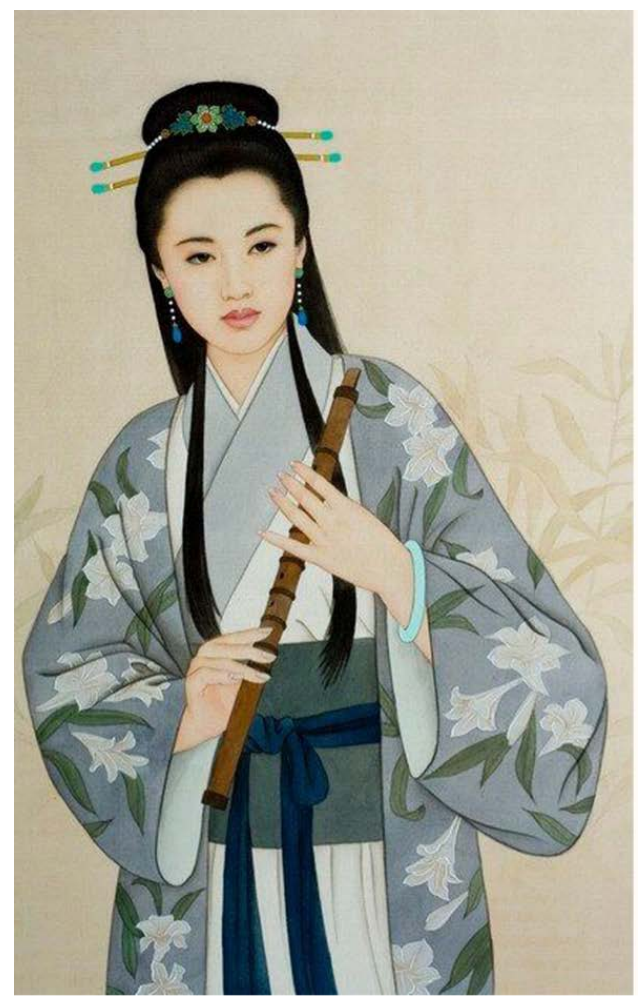

\section{Chinese traditional collar}

Overlapping collar (交领)

It is a typical feature of Han clothes in traditional Han clothes. The collar means that the front of the dress intersects left and right. The garments of Han clothing are generally covered to the right (the left front is covered with the right armpit and the right is covered.), Called the "right lapel", some ancient Chinese costumes are left covered, called the "left lapel".
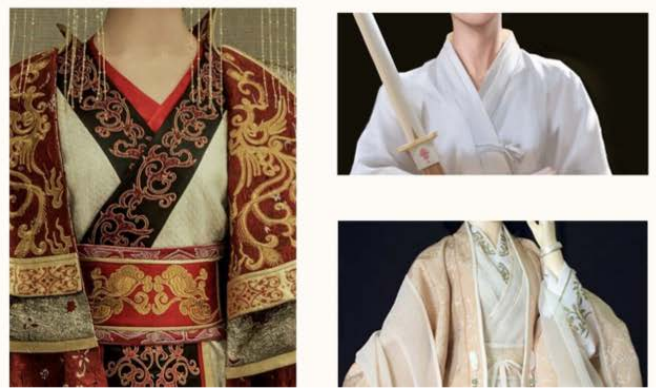

Figure 9. Chinese-traditional clothing elements-Chinese traditional collar (https://cuadernoderetazos.wordpress.com/pintura/huixuan\%C2\%A0zhao/). 


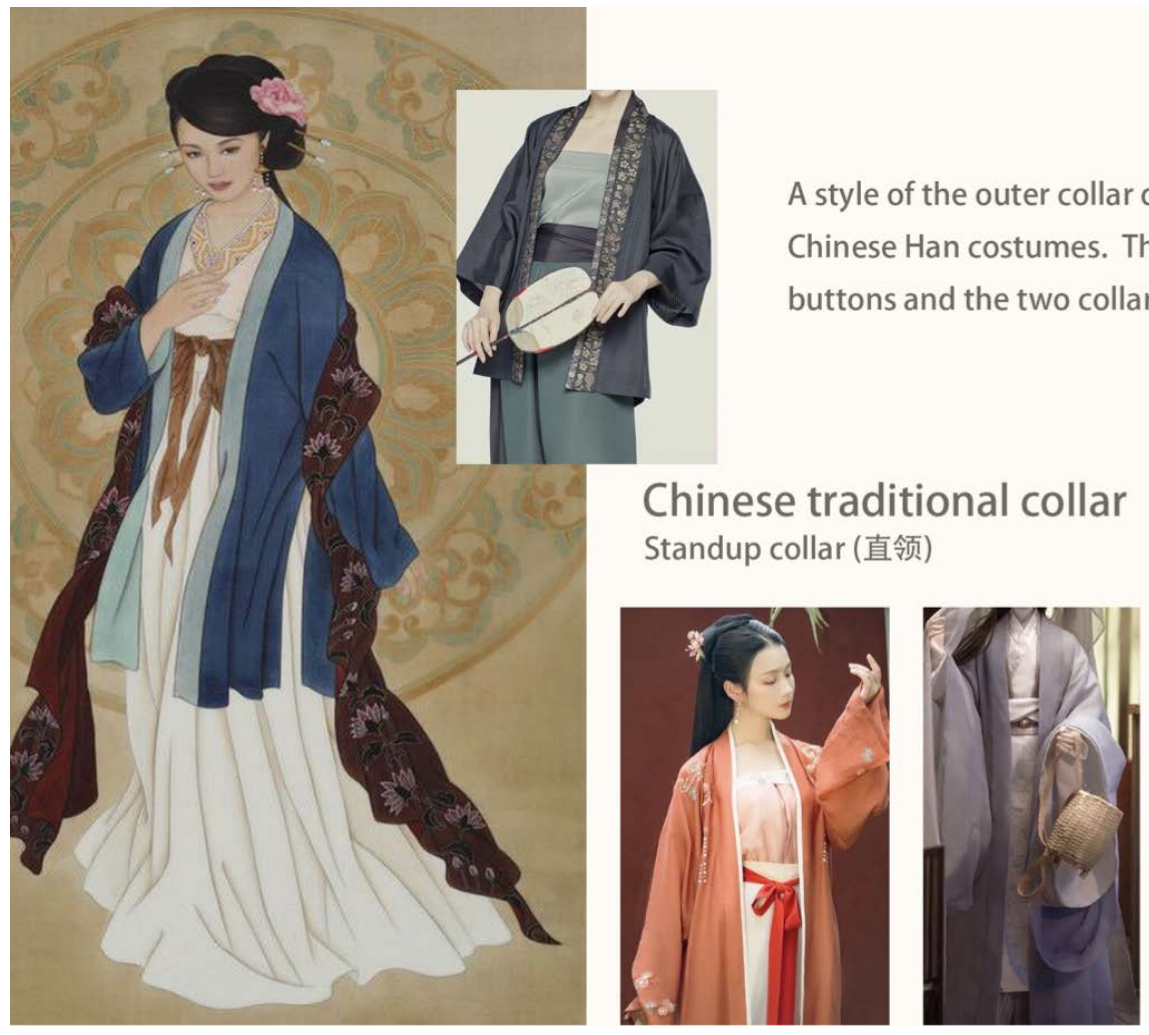

Figure 10. Chinese-traditional clothing elements-Chinese traditional collar (http://www.spring-sounds.com).

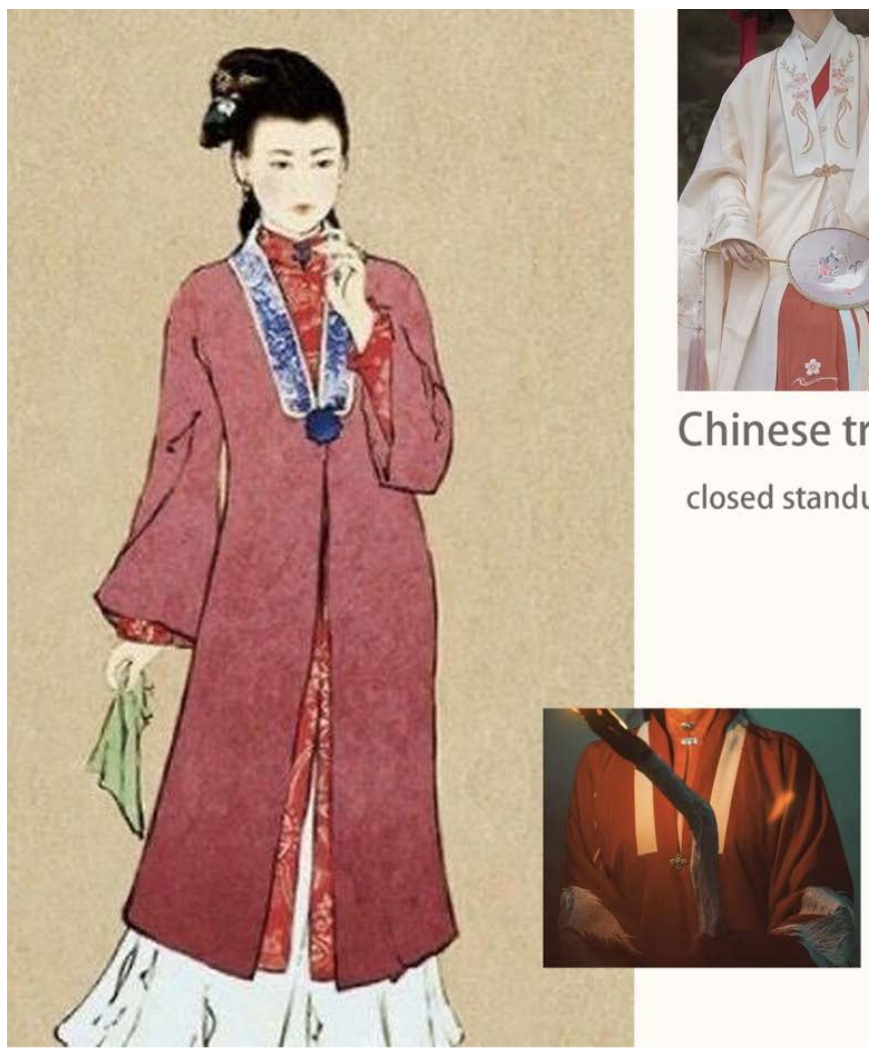

There are straps or buttons on the base of the standup collar, usually in the lower part of the chest. The top of the strap or buckle is a lapel, which will be decorated with patterns or embroidery, and the bottom half has no buttons.

Figure 11. Chinese-traditional clothing elements-Chinese traditional collar. 


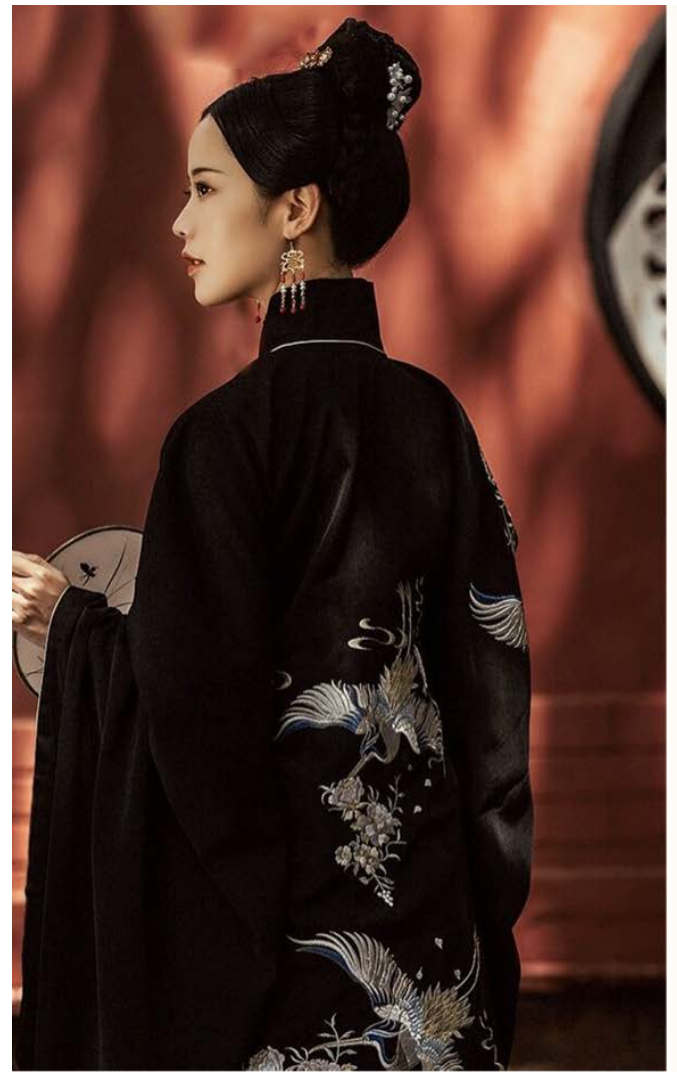

\section{Chinese traditional pattern Egret}
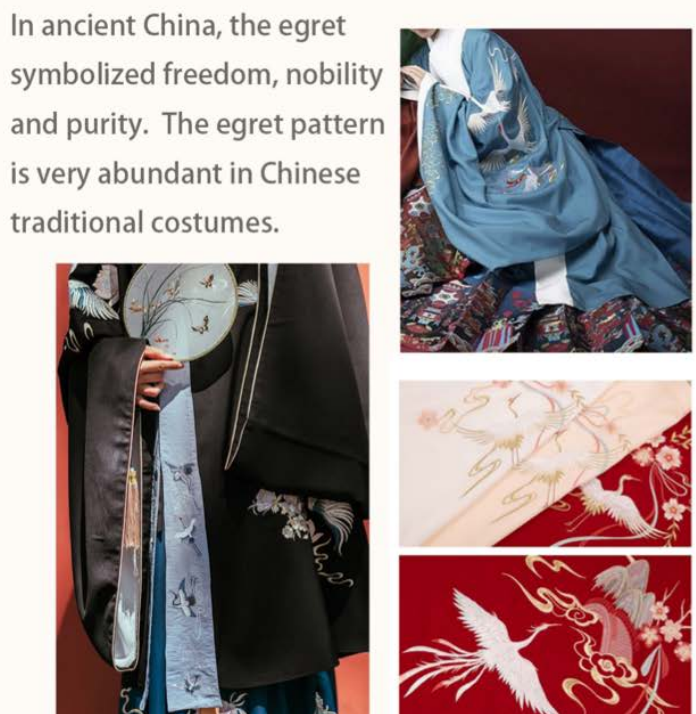

Figure 12. Chinese-traditional clothing elements-Chinese traditional collar.
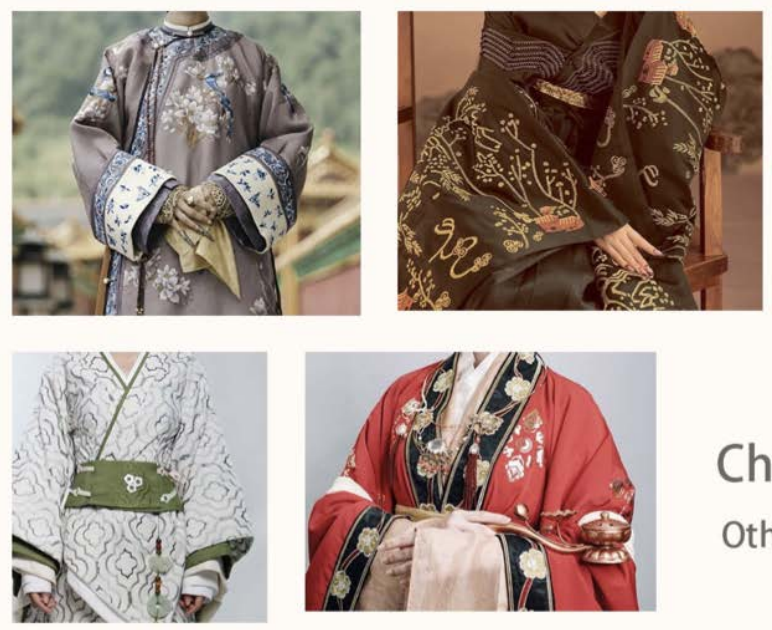

\section{Chinese traditional pattern}

Other patterns
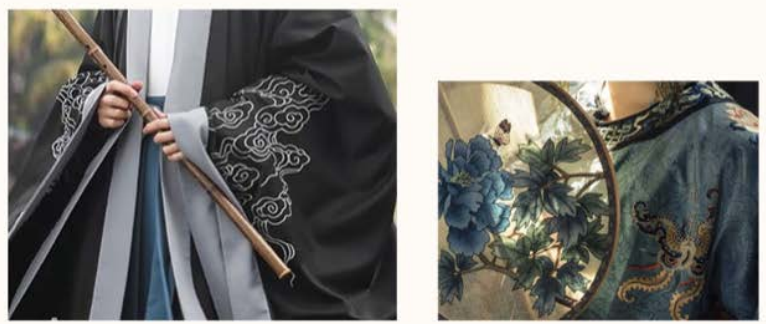

The patterns of traditional Chinese costumes are mostly complex and changeable, the lines are changeable but there is no lack of beauty, and the distribution is basically symmetrical.

Figure 13. Chinese-traditional clothing elements-Chinese traditional collar (https://ancient-china.tumblr.com). 


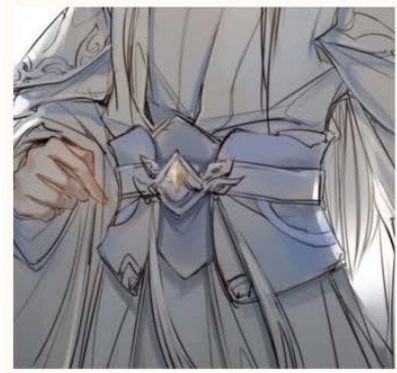

\section{Chinese traditional accessories}

\section{Traditional belt}
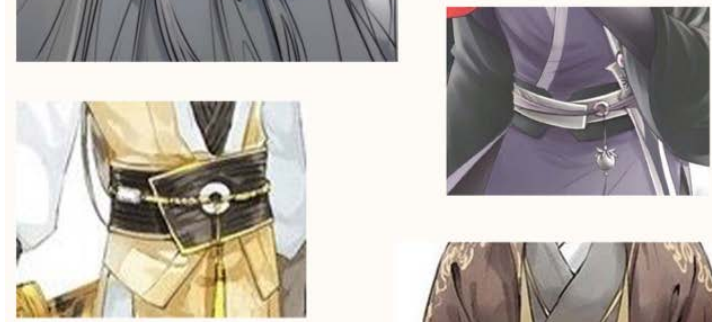

In the early days of China, most of the clothes did not need buttons,

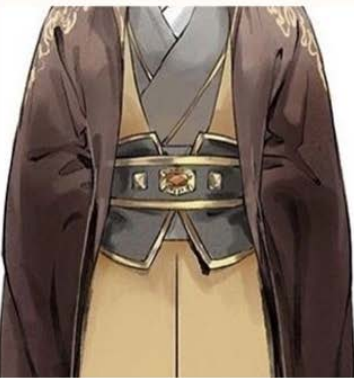
and only a few small bands were sewn on the placket to tie them. In order not to loosen the clothes,

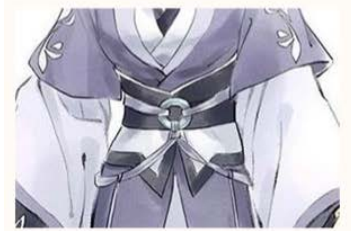
people put a large belt around their waist again.

Figure 14. Chinese-traditional clothing elements-Chinese traditional collar (http://bjdcollectasy.com/2019/11/22/doctor-youzhi/ and https://www.artstation.com/artwork/v1xgkY).

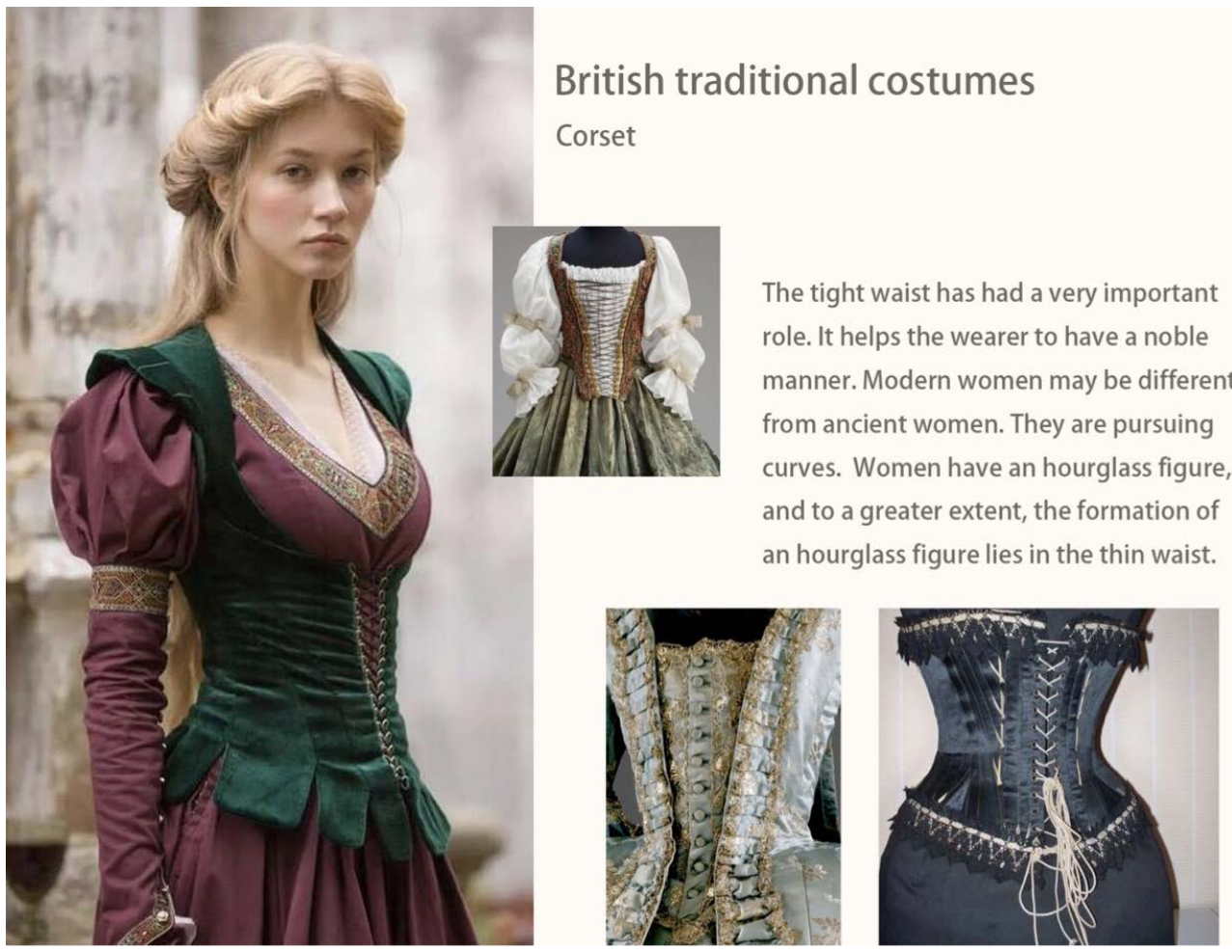

Figure 15. British traditional clothing elements-Corset (https://www.devilnight.co.uk/victorian-ball-gowns/4288-black-masked-ball-gothic-victorian-costum e-dress.html). 


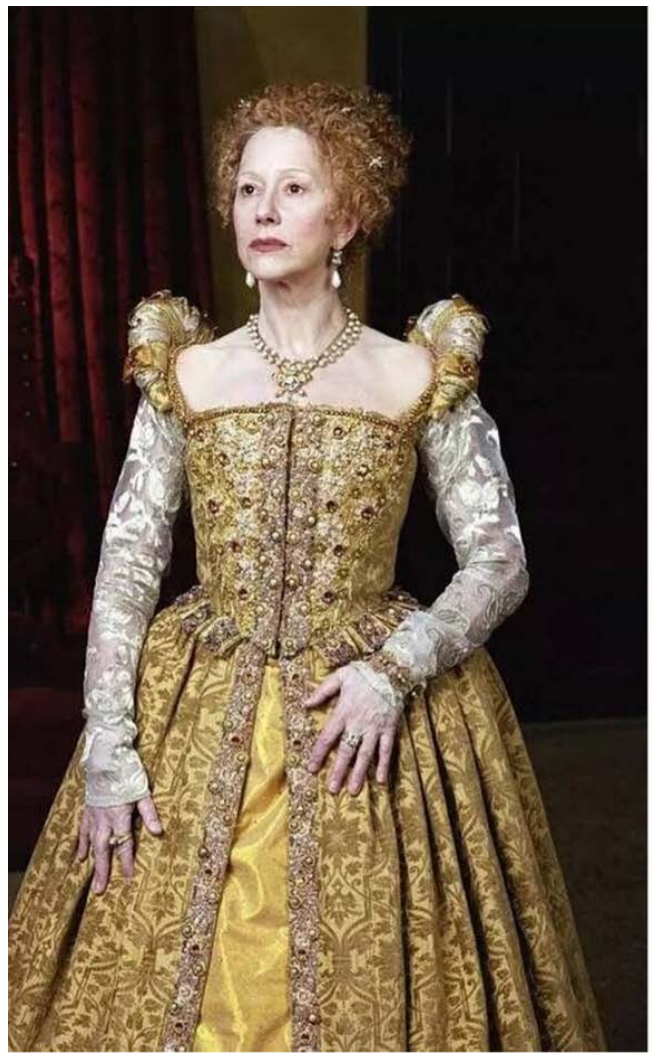

\section{British traditional costumes \\ Tudor dynasty}
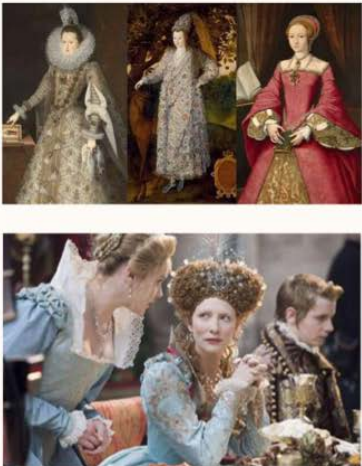

Tudor dynasty can be described as the most beautiful period in British history. In the clothing, women's clothing began to become complex, and became more and more luxurious. The fabrics were more inclined to glossy brocade, silk and velvet.

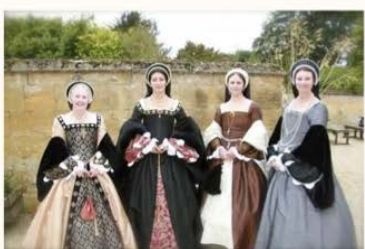
Flare sleeves, low chest square collar, shoulder pads that rise upwards, and lace are all essential.

Figure 16. British traditional clothing elements-Tudor dynasty costume.

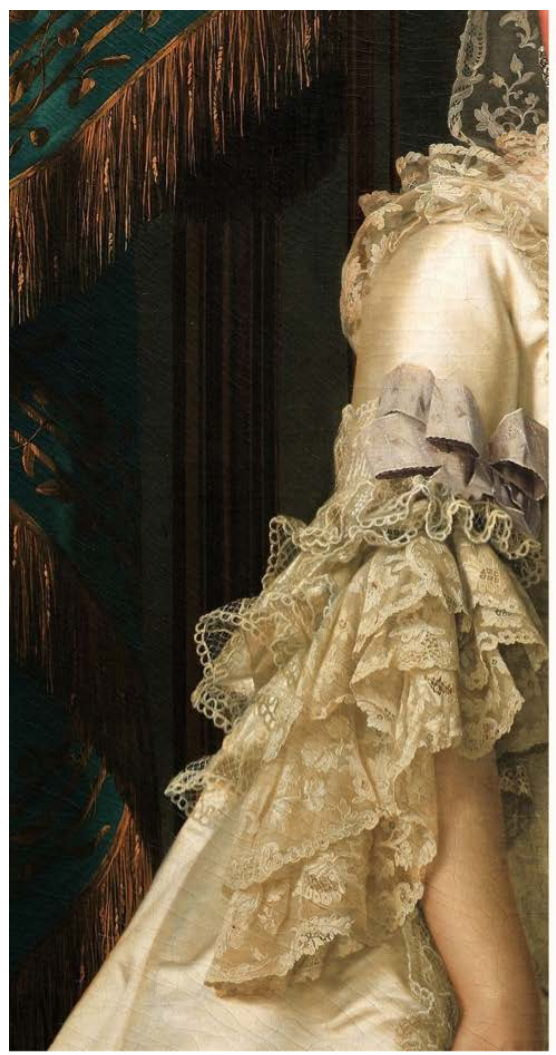

\section{British traditional costumes}

Multi-layered lace cuffs
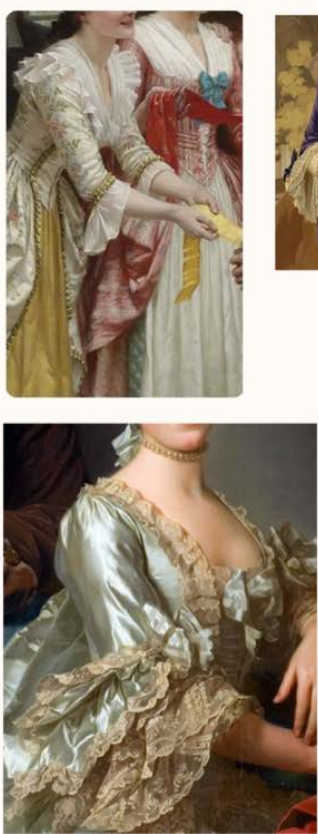

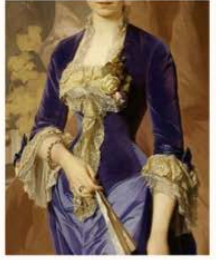

The Georgian costumes were more elegant and tended to French style. The skirt is still gorgeous, the sleeves with multi-layered lace cuffs and the low-cut large neckline design were the mainstream at that time.

Figure 17. British traditional clothing elements-multi-layered lace cuffs. 


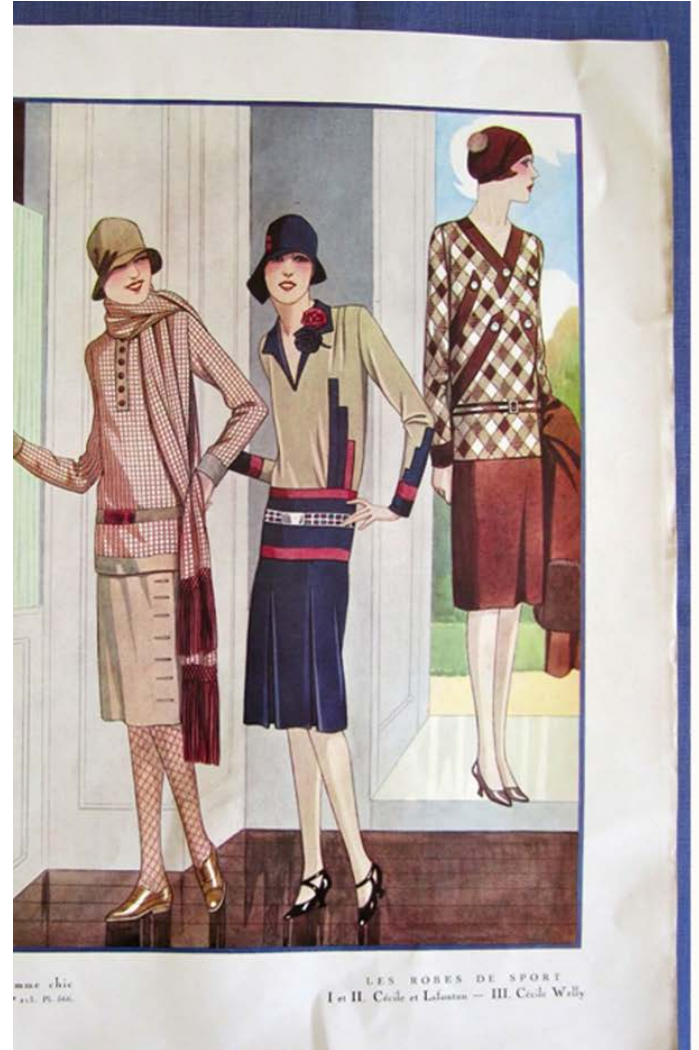

\section{British traditional costumes \\ Jazz style}

By the 1920s, influenced by Arab

culture, women's clothing was full

of exoticism. Under the wide clothing, a charming jazz style was born.
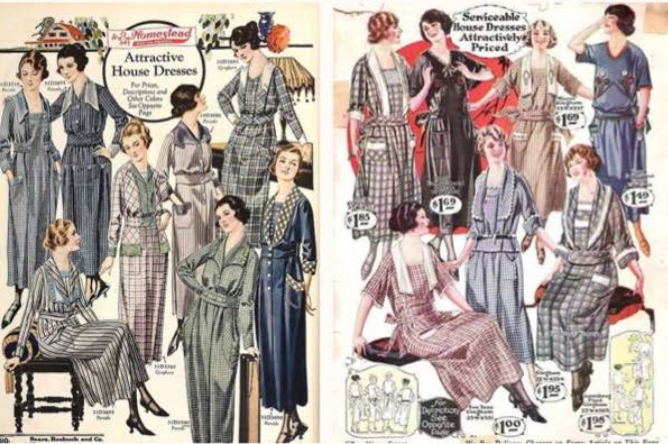

Figure 18. British traditional clothing elements-Jazz style.
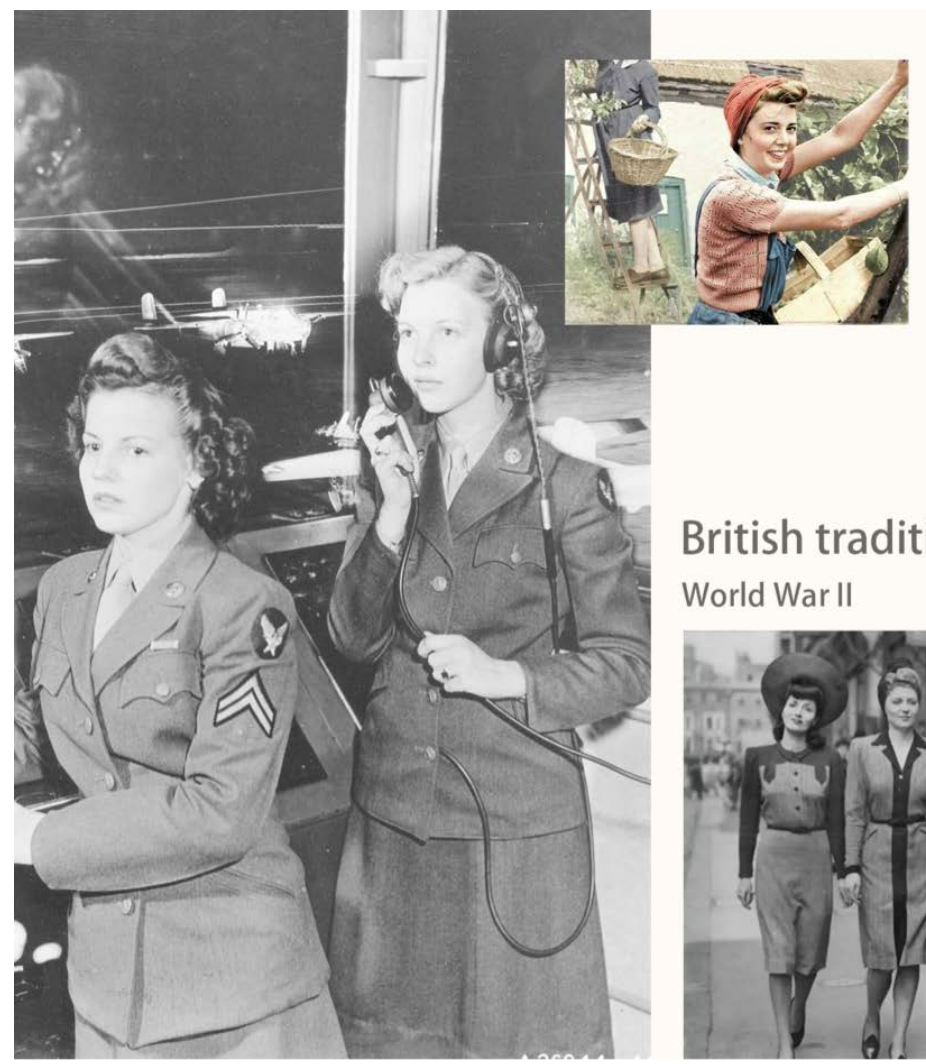

Under the shadow of the war, Britain, which is in short supply of materials, has no enough cloth to design complex fashion. Replaced by short shirts, jackets, and simple dresses. As men have entered the battlefield, women have become the main force of the factory. Tooling and hair bandanas became the main wear at that time.

\section{British traditional costumes}

World War II
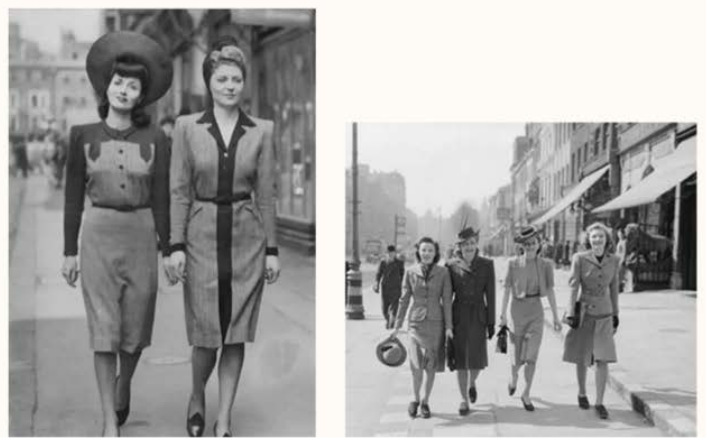

Figure 19. British traditional clothing elements-multi-World War II. 

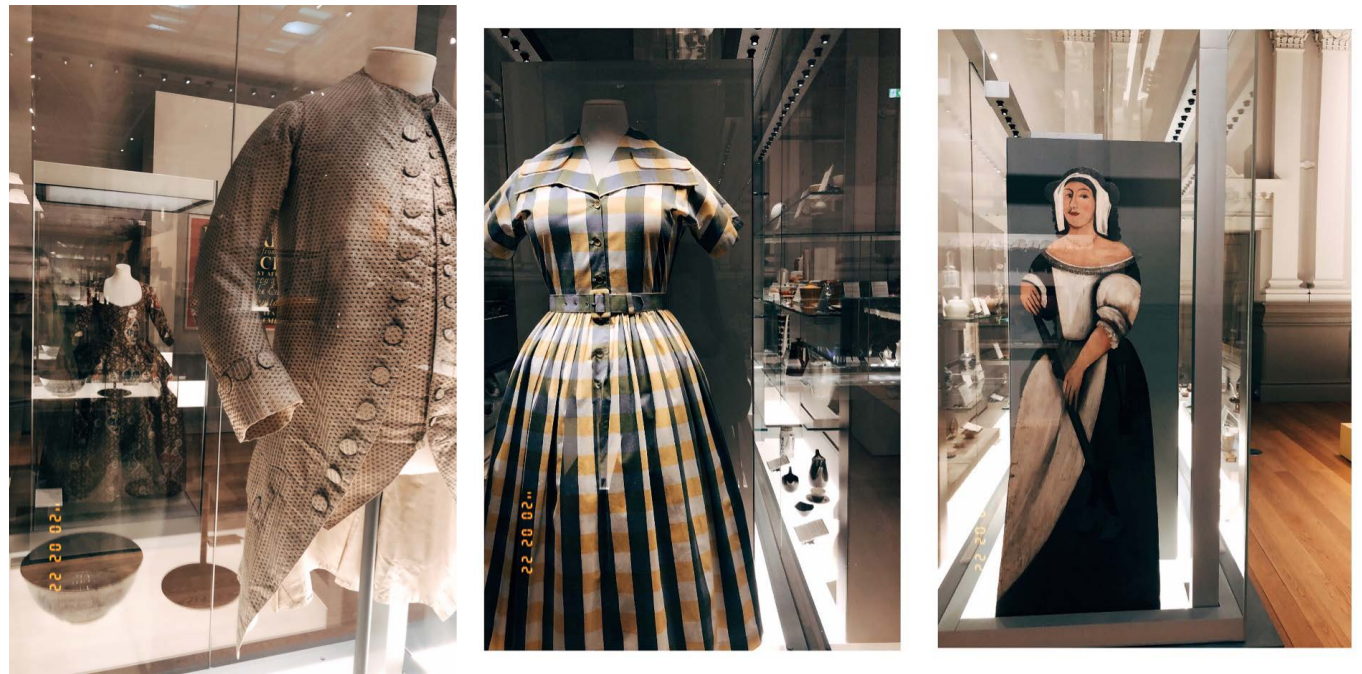

Figure 20. British traditional clothing elements-multi-World War II.

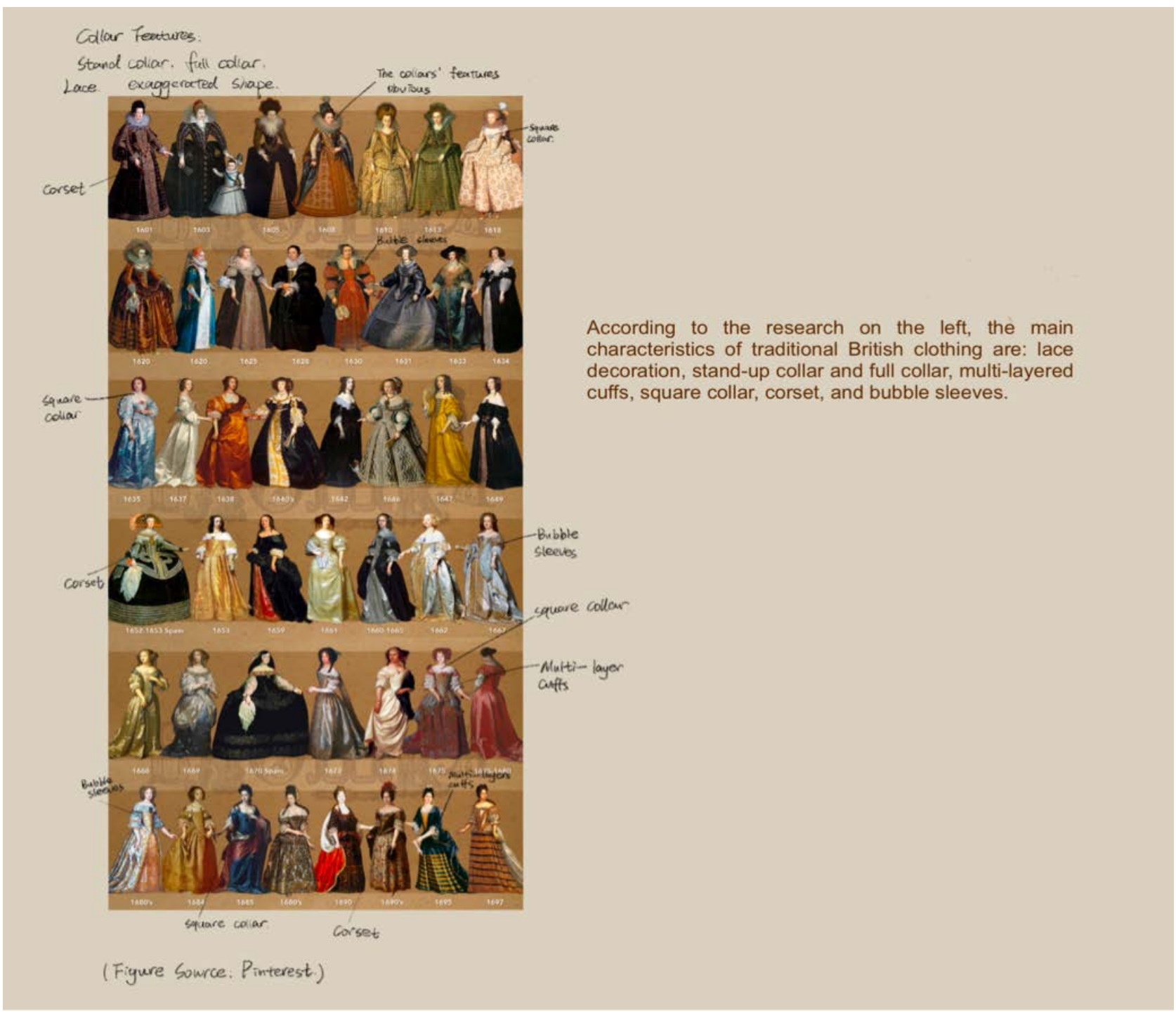

Figure 21. The development process of clothing in different periods of China. 

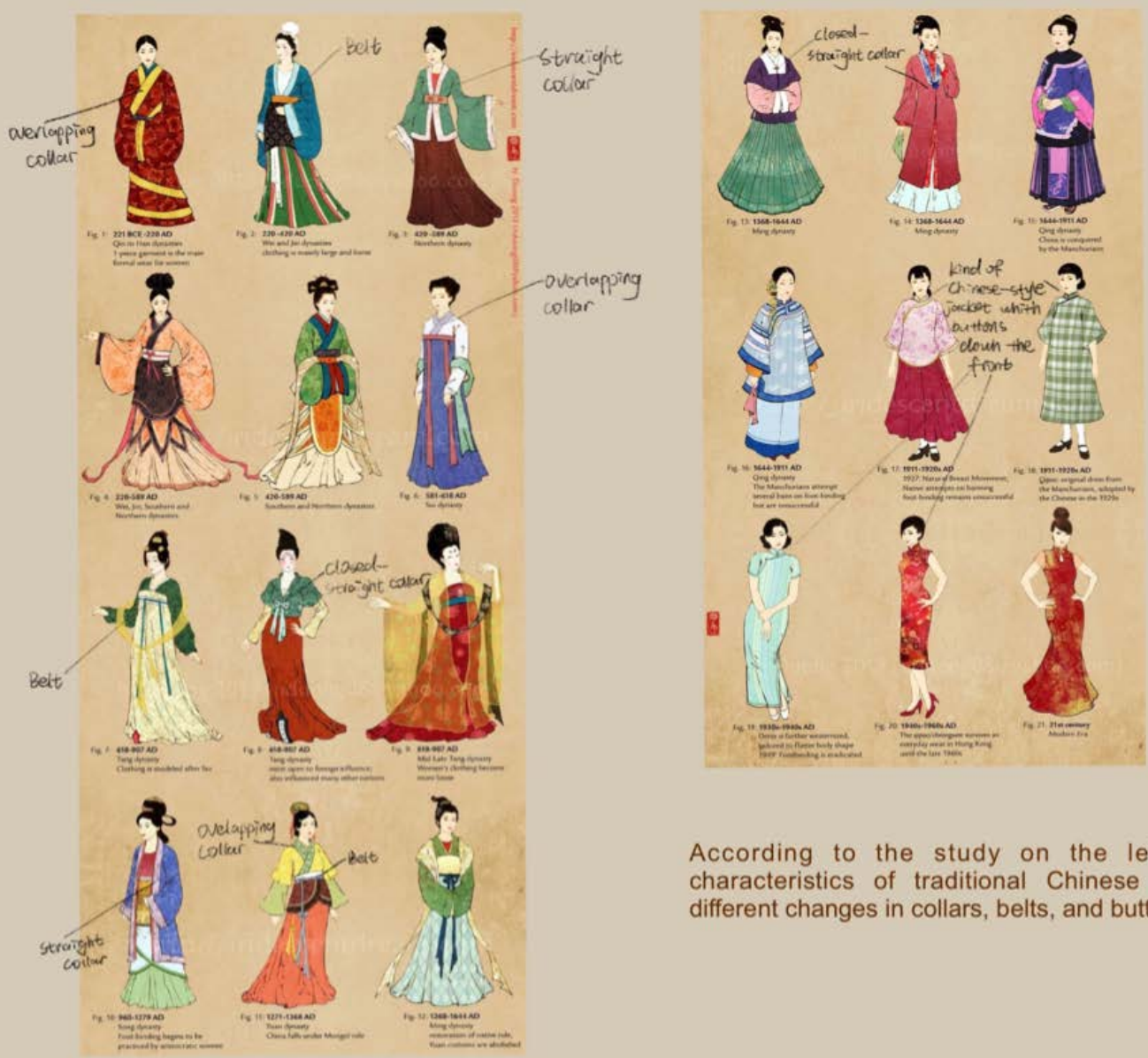

According to the study on the left, the main characteristics of traditional Chinese clothing are: different changes in collars, belts, and buttons.

(Figure soure: Pinterest)

Figure 22. Timeline of traditional Chinese clothing and features.

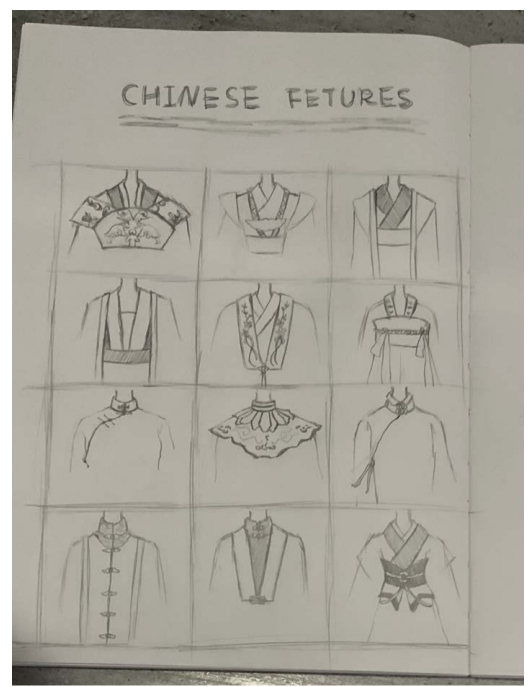

Figure 23. Some sketches about traditional costumes of design points. 


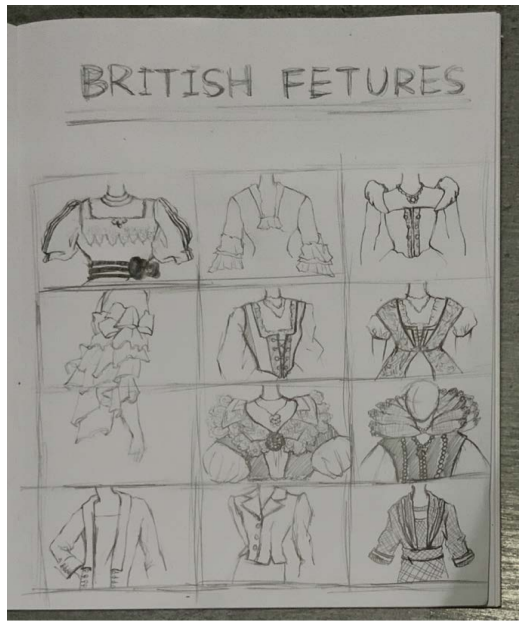

Figure 24. Some sketches about traditional costumes of design points.

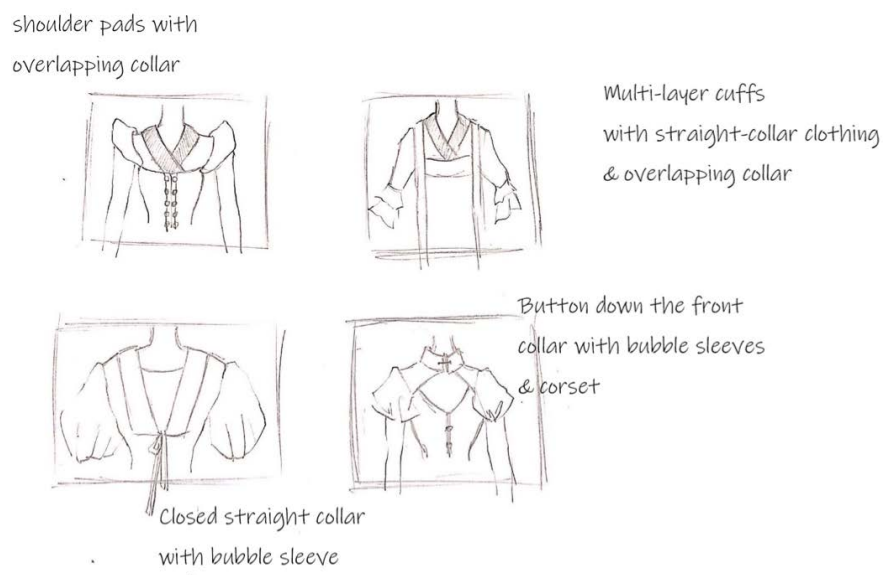

Figure 25. Sketches of shoulder pads with overlapping collar.
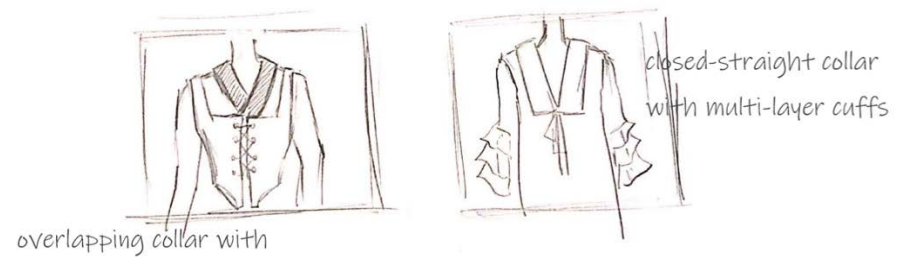

corset

buttons down the front collar

buttons down the front

with corset.
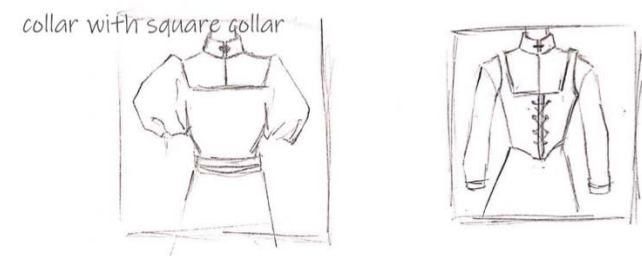

Figure 26. Sketches of collar and buttons. 
These classic elements of traditional costumes not only have different aesthetics and ornamental features, but also it is difficult to see these designs in the contemporary era, so such an attempt is very necessary.

After trying some drafts, I screened out some of the more attractive design styles, which are in line with contemporary daily wear, and then proceed to the next design (see Figures 27-29).

\subsection{Final Design}

\subsubsection{Colors}

Traditional Chinese color: Yuanshan Purple (see Figure 30). Colors are commonly used in Chinese landscape painting.

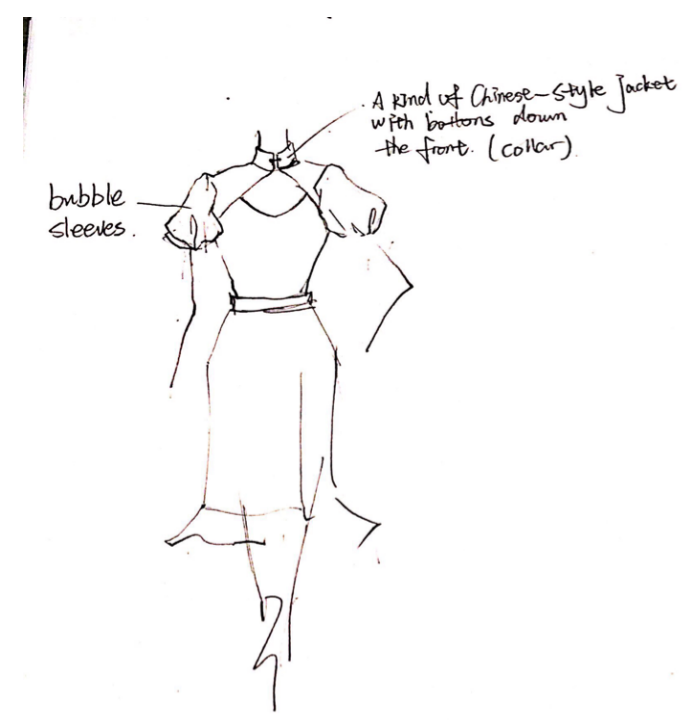

Figure 27. Timeline of traditional British clothing and features.

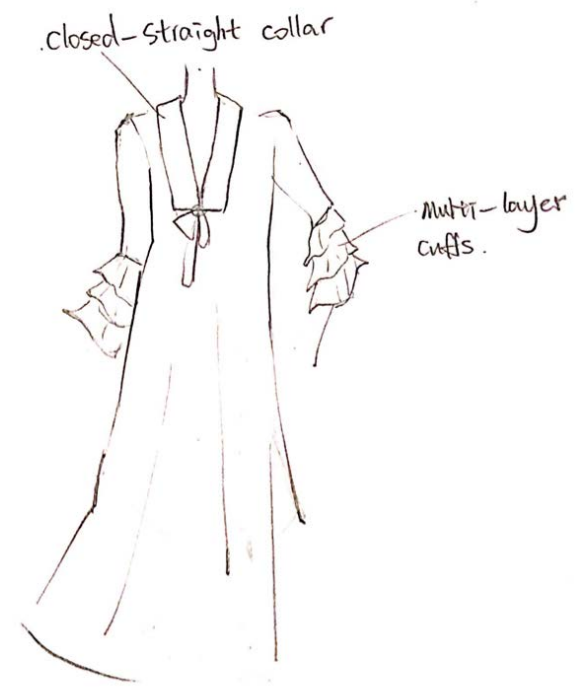

Figure 28. Timeline of traditional British clothing and features. 


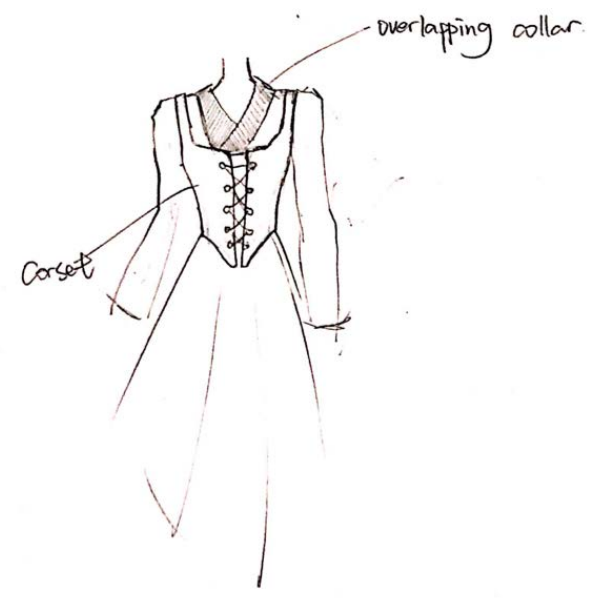

Figure 29. Timeline of traditional British clothing and features.

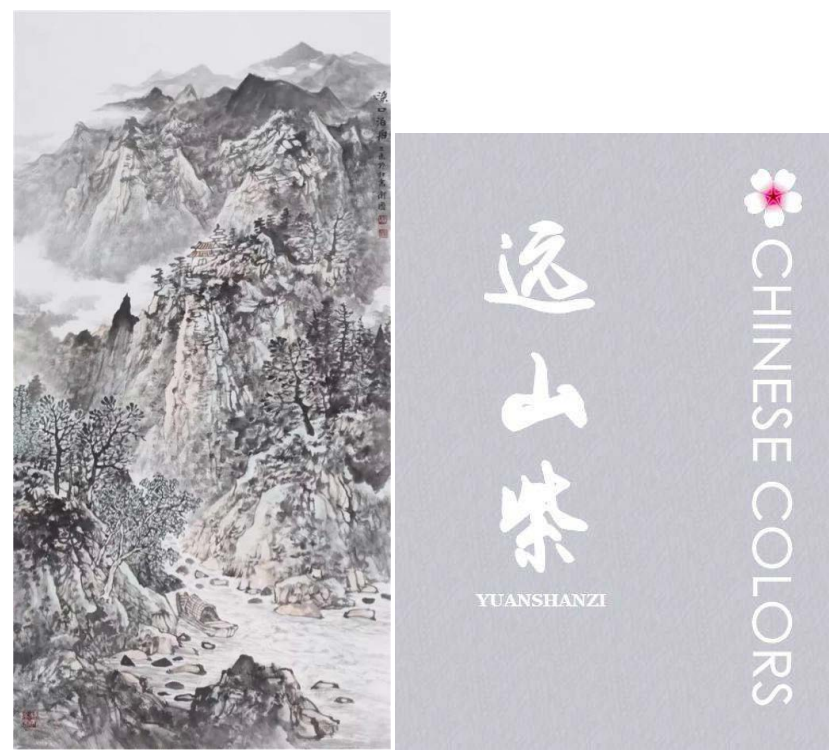

Figure 30. Yuanshan purple.

Blue: British royal favorite color (see Figure 31). Blue has a little-known symbolic meaning in the UK-loyalty.

White implies justice, purity, dignity, integrity, youthfulness, transcendence and worldly emotions. White represents purity and symbolizes holy elegance.

\subsubsection{Fabric}

Silk is a special product of China (see Figure 32). The working people of ancient China invented and produced silk products on a large scale. It also opened the first large-scale trade exchange between East and West in the history of the world.

Widely used in traditional British clothing, lace decoration (see Figure 33) can be seen everywhere on cuffs, waist, neckline and body. 
For plain weave, transparent, after dyeing, the color is bright and the texture is light (see Figure 34). It is a very popular fabric in the clothing industry today.

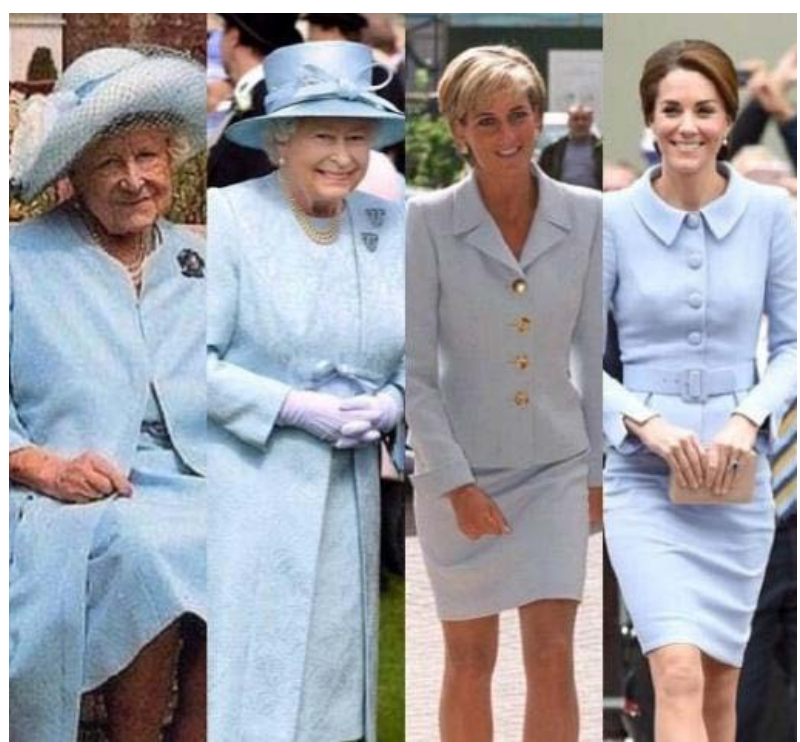

Figure 31. British royal blue.

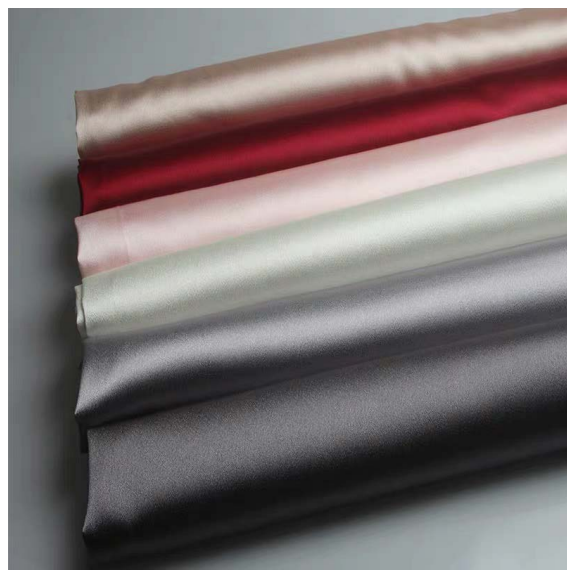

Figure 32. Chinese silk.

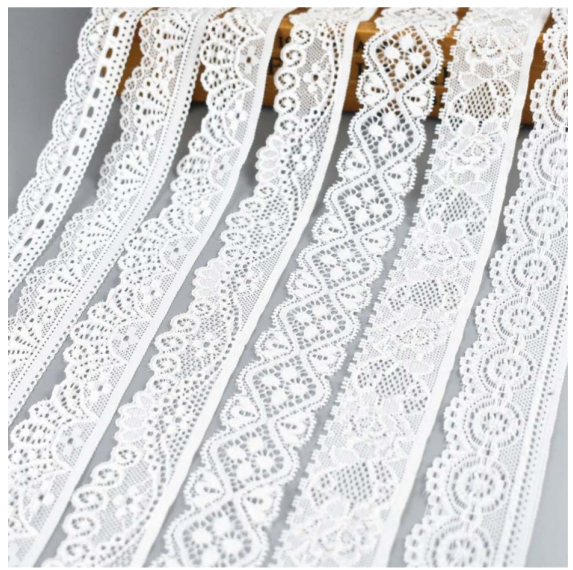

Figure 33. Lace decoration. 


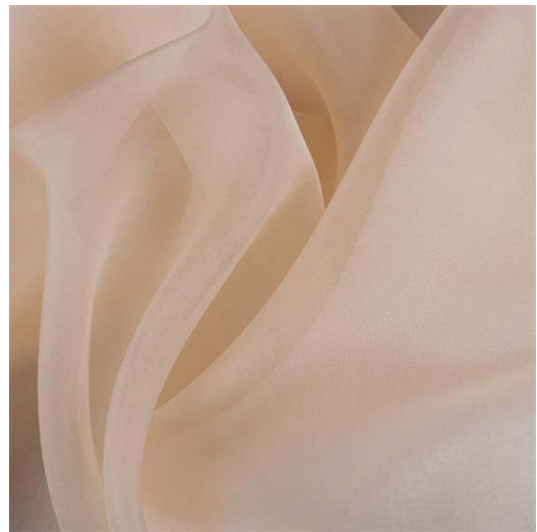

Figure 34. Chinese silk.

\subsubsection{Final Design \& Explanation (Shown in Figures 35-37)}

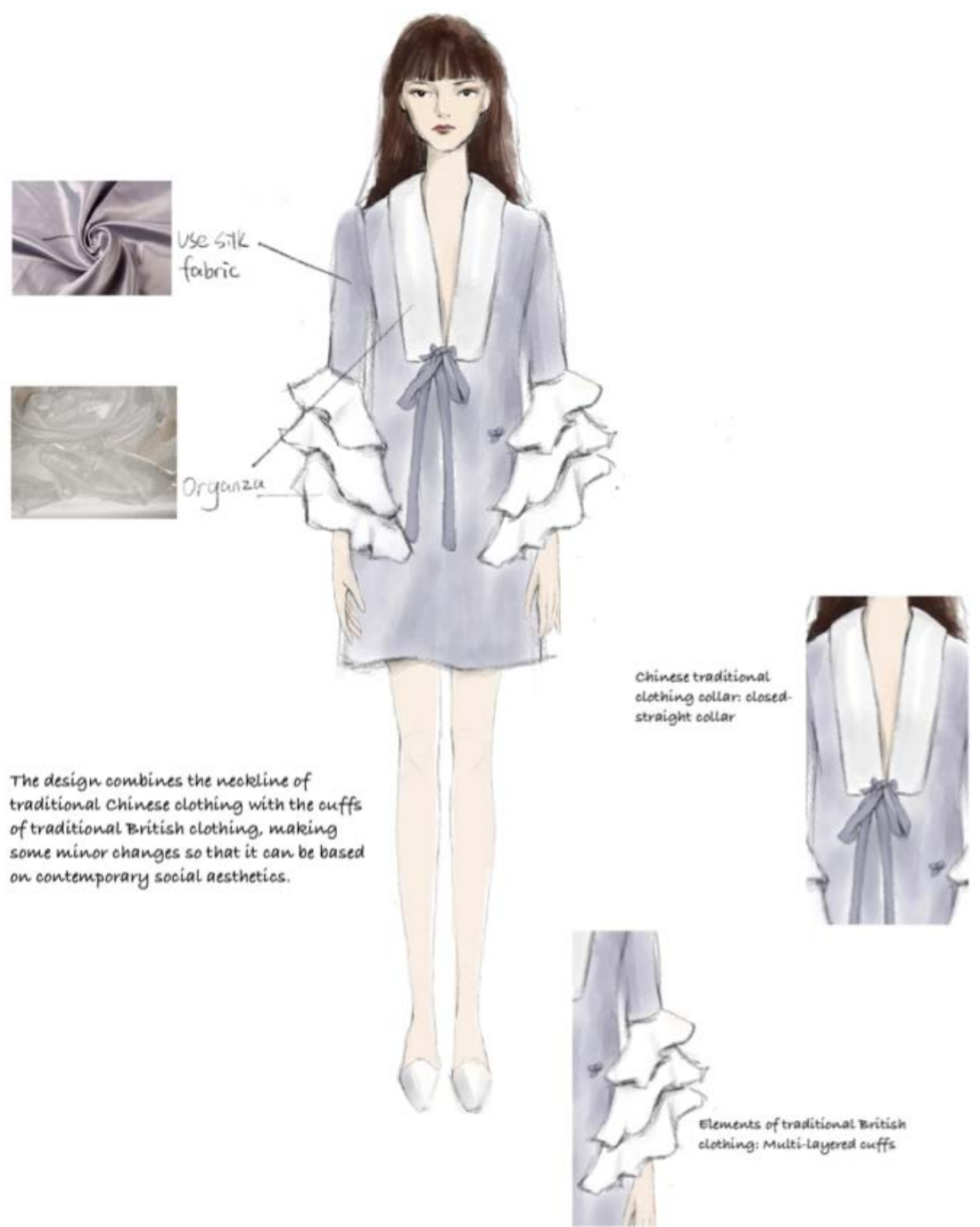

Figure 35. Final design 1. 


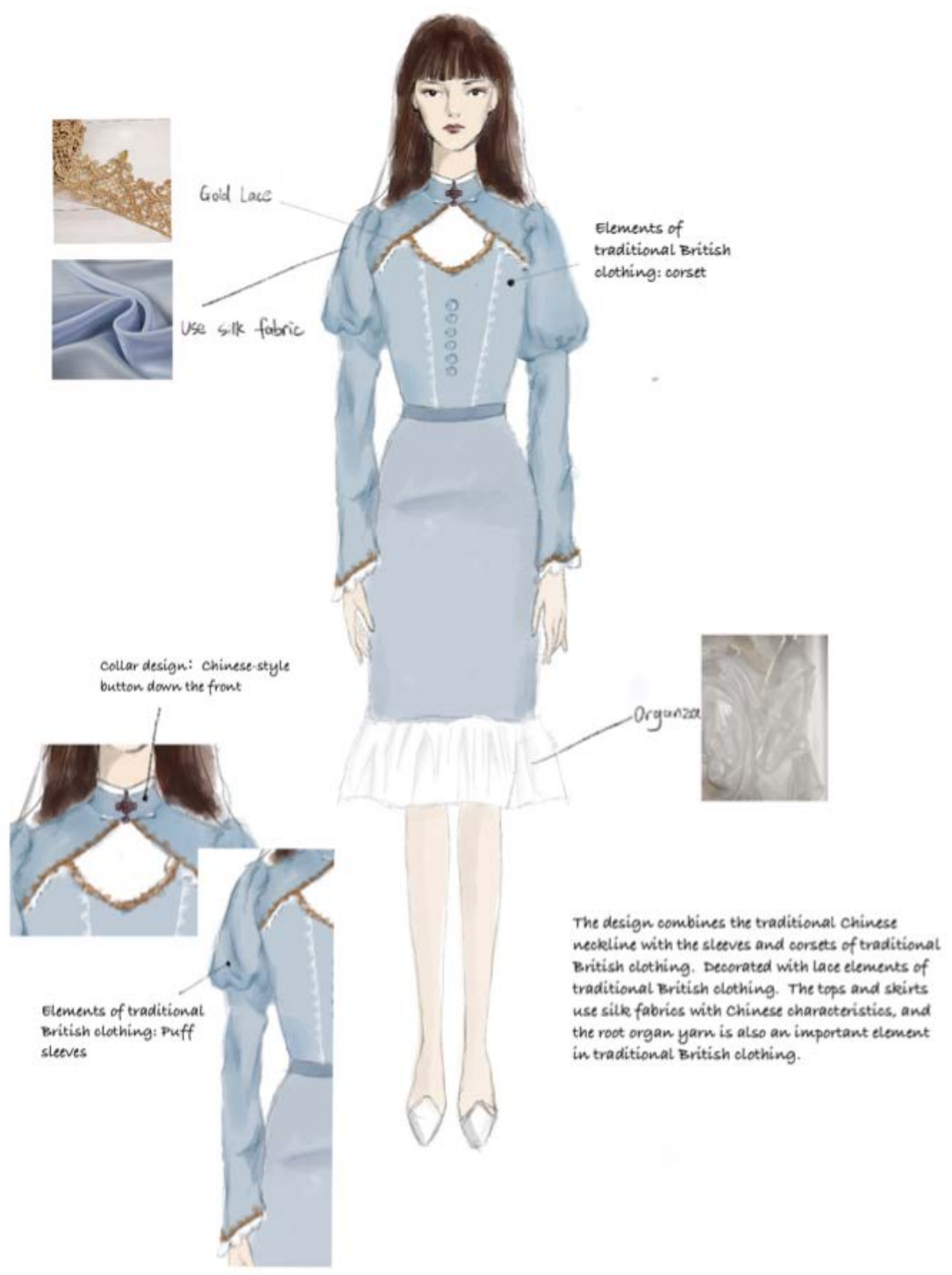

Figure 36. Final design 2.

\section{Conclusion}

Reflection: My design thinking has been broader and deeper than before through this semester of study. At the same time, I changed my design vision to connect design to contemporary society. In this series of research, I used various research methods, and at the same time, I applied these methods step by step to my personal development projects. It helps to realize my future design further.

About this design: It is unique because it combines traditional costumes from China and the United Kingdom, and there are very few such designs on the market. The display of different cultural elements in clothing reflects cultural diversity. I hope to design more fusion of cultural elements. 


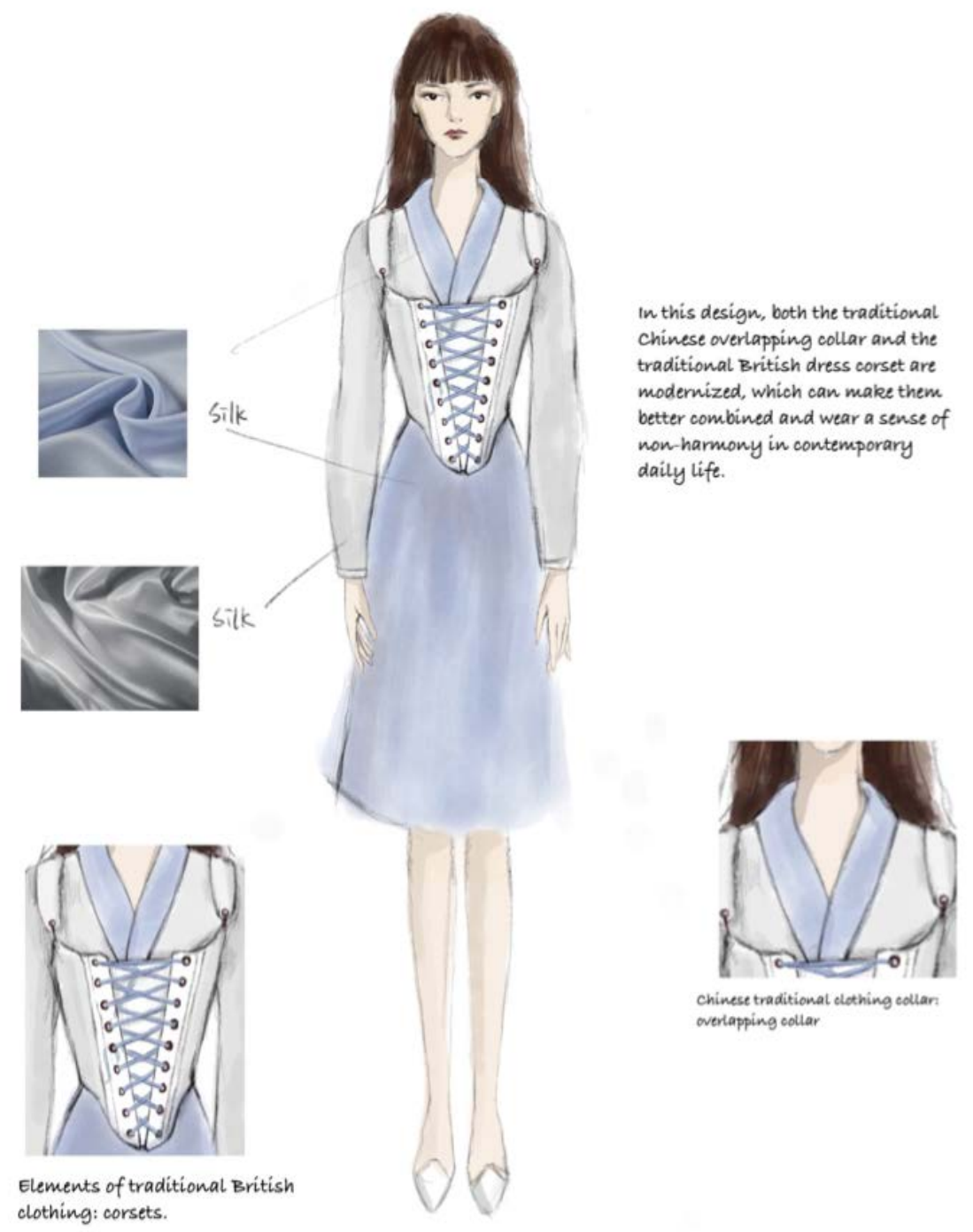

Figure 37. Final design 3.

\section{Conflicts of Interest}

The author declares no conflicts of interest regarding the publication of this paper.

\section{References}

Francois, S. (2019). World Economic Forum: Environment and Natural Resource Security.

Jin, B. (2004). Apparel Industry in East Asian Newly Industrialized Countries: Competitive Advantage, Challenge and Implications. Journal of Fashion Marketing and Management, 8, 230-244. https://doi.org/10.1108/13612020410537915

Lee, S. H., \& Song, H. K. (1994). The Korean Garment Industry: From Authoritarian Pa- 
triarchism to Industrial Paternalism. In E. Bonacich, L. Cheng, N. Chinchilla, N. Hamilton, \& P. Ong (Eds.), Global Production: The Apparel Industry in the Pacific Rim (pp. 147-161). Temple University Press.

Peterson, M. (1997). Confucianism. In J. H. Koo, \& A. C. Nahm (Eds.), An Introduction to Korean Culture (pp. 137-151). Hollym International Corporation.

Sung, Y., \& Tinkham, S. F. (2005). Brand Personality Structures in the United States and Korea: Common and Culture-Specific Factors. Journal of Consumer Psychology, 15, 334-350. https://doi.org/10.1207/s15327663jcp1504_8

Tivel, D. (2012). Evolution: The Universe, Life, Cultures, Ethnicity, Religion, Science, and Techologyte (p. 117). Dorrance Publishing Co., Inc.

\section{Link References}

https://cuadernoderetazos.wordpress.com/pintura/huixuan\%C2\%A0zhao/

https://imgur.com/gallery/143zF

https://changan-moon.tumblr.com/post/135521586943/traditional-chinese-hanfu-in-son g-dynasty-and-ming

http://www.spring-sounds.com/goods.php?id=635

https://www.artstation.com/artwork/v1xgkY

http://bjdcollectasy.com/2019/11/22/doctor-youzhi/\#foobox-1/0/ls_doctoryouzhi_16.jpg

https://ancient-china.tumblr.com/

https://www.devilnight.co.uk/victorian-ball-gowns/4288-black-masked-ball-gothic-victor ian-costume-dress.html 


\section{Appendix}

\section{Appendix 1}

\section{Brief:}

\section{A: PROJECT BACKGROUND}

With the progress of globalization, the mutual integration of cultures has become more and more popular. At the same time, clothing has also become a part of world cultural exchanges.

Nowadays, the influence of Chinese culture is gradually expanding in the UK, and Chinatown has also begun to develop. Many products with Chinese design attracted the attention of the British, which also means that Chinese culture continues to develop and spread in the UK.

\section{B: AIM}

The goal is to blend Chinese traditional culture with British culture and embody it in fashion design.

\section{C: PROJECT OBJECTIVE}

Design a design with traditional clothing elements in combination with contemporary society.

Bring Chinese cultural diversity into clothing.

Chinese culture: China has a long history, and clothing has different characteristics at different historical stages. Mainly lies in the collar structure, patterns, belt accessories and colors.
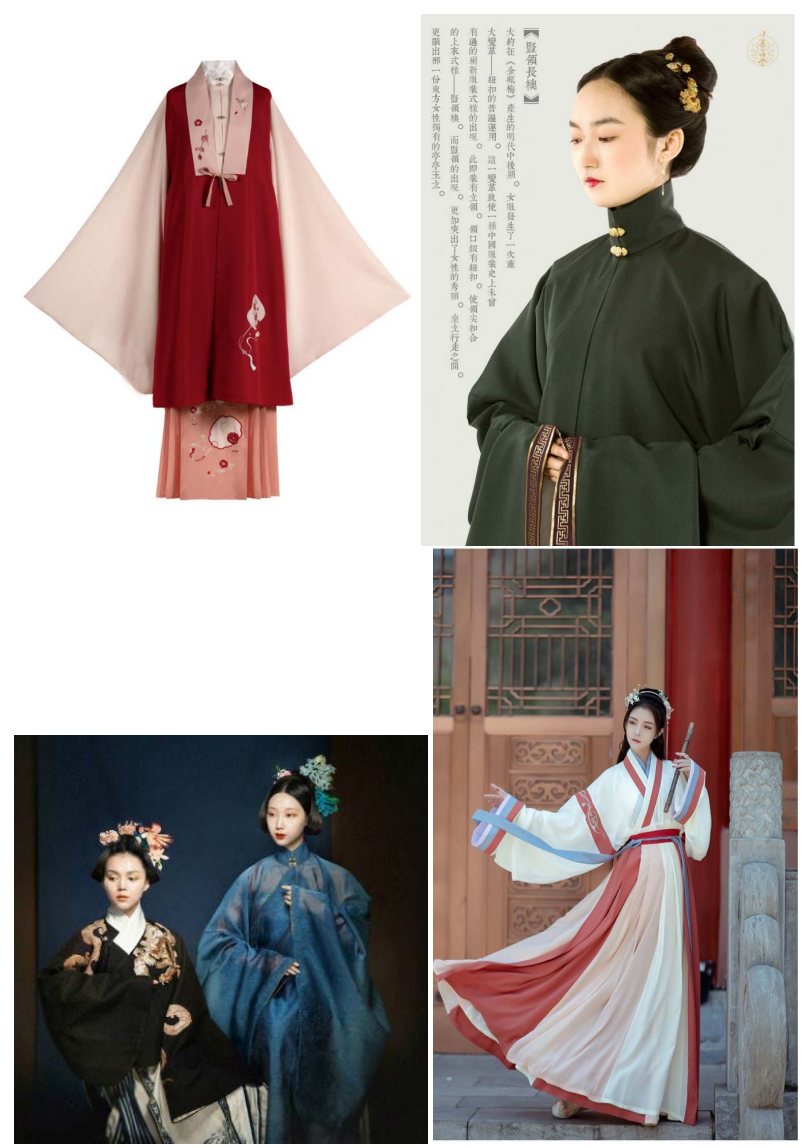
British culture: In the course of this project, not only the collection of Chinese elements but also the research of British clothing needs to be from traditional to modern. In the process, in addition to collecting pictures online, I also saw related British classical costumes in the exhibition hall.

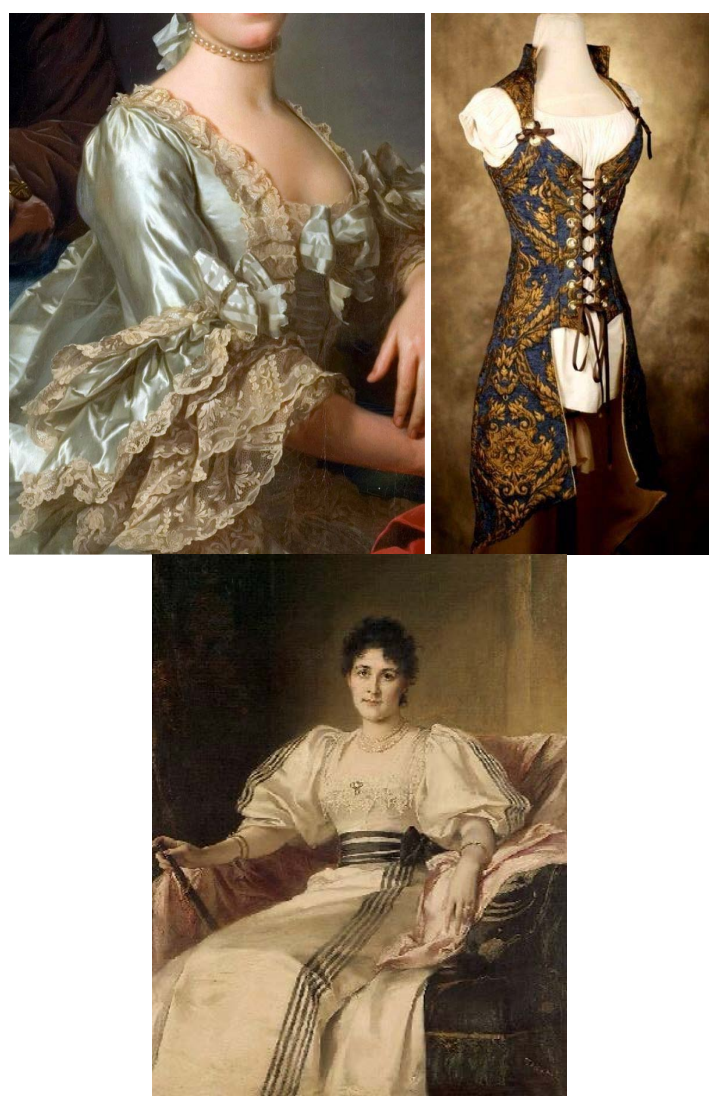

Extraction of design points: According to the research findings, I have developed some design points from the clothing characteristics of the two countries with sketches.

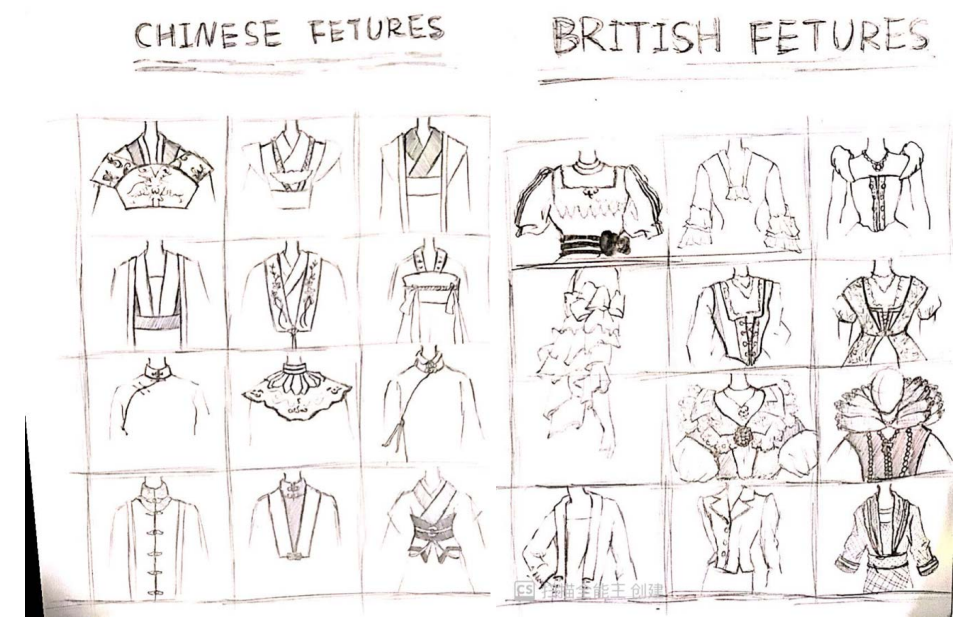

Initial design: screening of the first draft 

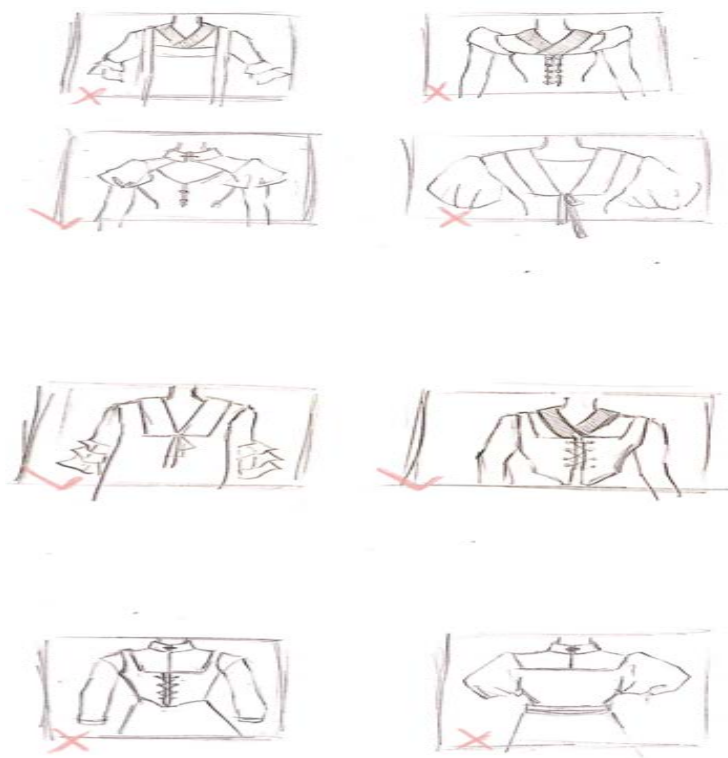

\section{Develop design:}
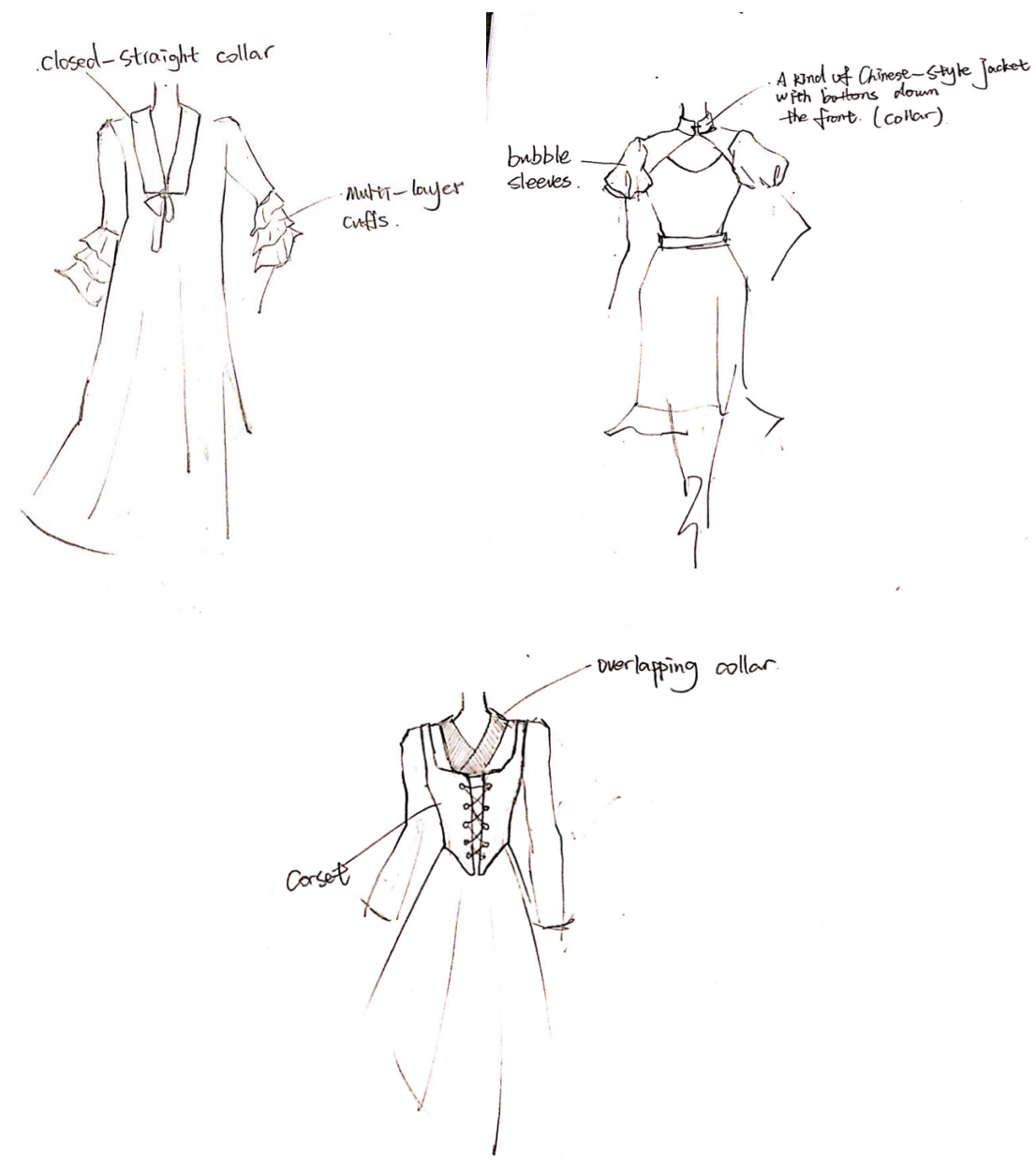

Final design: 

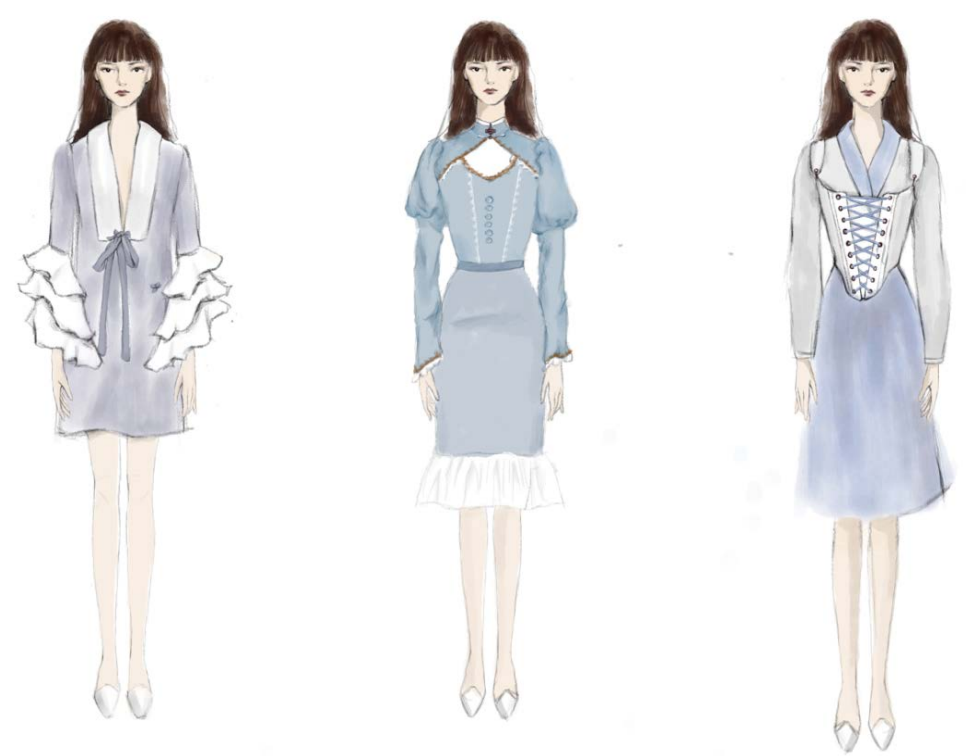